“Como Eu ESCREvo"

Richard Posner

Tradução de Ana Caroline Pereira Lima

Thiago Santos Aguiar de Pádua

Boola!

Duncan Kennedy

Tradução de Ana Caroline Pereira Lima

Thiago Santos Aguiar de Pádua

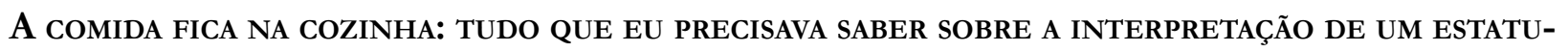
TO EU APRENDI QUANDO TINHA 9 ANOS

Hillel Y. Levin

Tradução de Jefferson Carús Guedes

Ana Caroline Pereira Lima

Thiago Santos Aguiar de Pádua

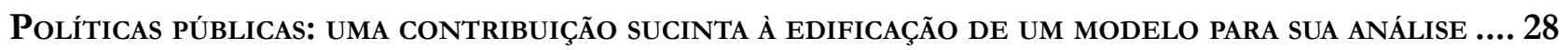

Victor Manuel Barbosa Vicente

1 Introdução

2 Politicas públicas: alguns modelos para sua análise ............................................................................29

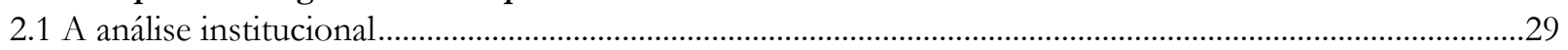

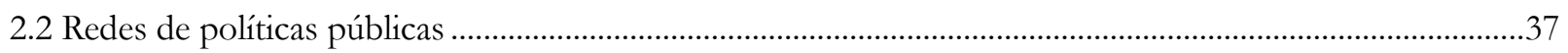

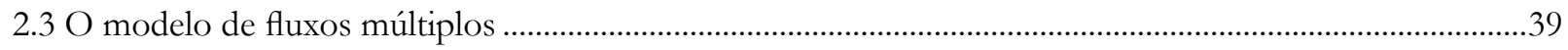

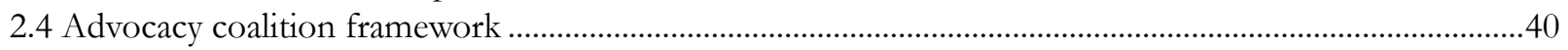

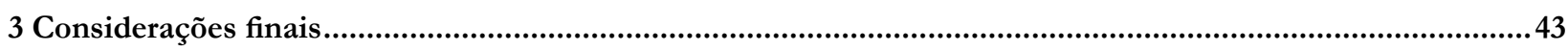

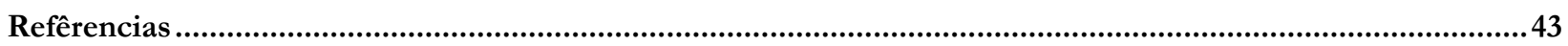

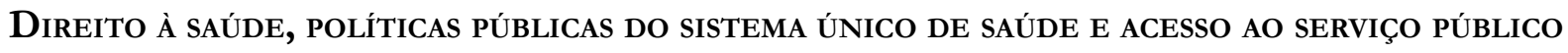

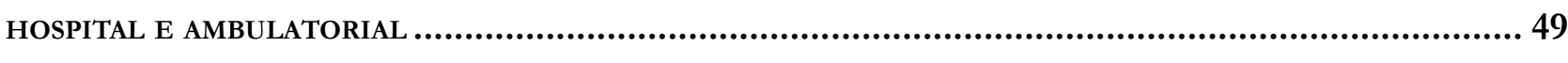

Emerson Affonso da Costa Moura

Fabrizia da Fonseca Passos Bittencourt Ordacgy

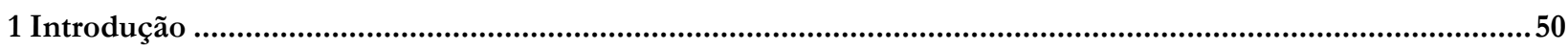

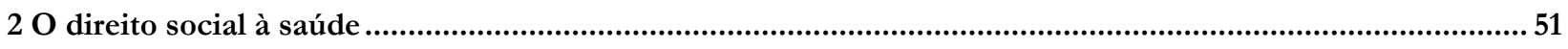

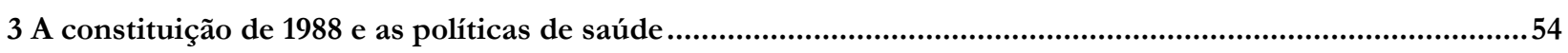

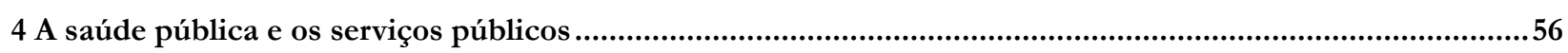

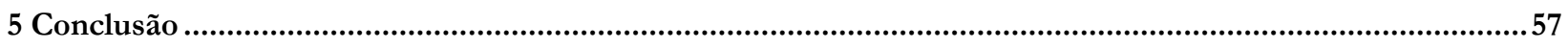

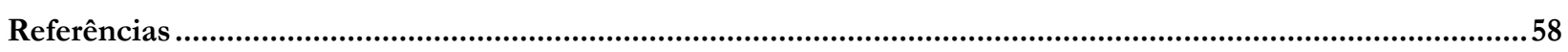

AUTISMO: O IDEAL E O REAL NA EFETIVAÇão DA DECISÃo JURISDiCIONAL QUE IMPLEMENTA POLÍtTICAS

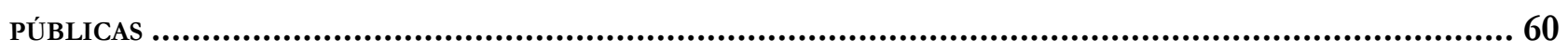

Grasielly de Oliveira Spínola

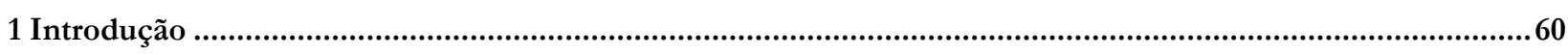

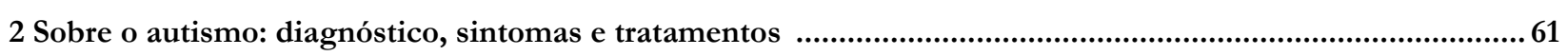


3 O controle jurisdicional de políticas públicas relacionadas ao autismo no Estado de São Paulo

$3.1 \mathrm{Da}$ ineficiência do julgado em razão da execução pela via individual ......................................................65

3.2 Dos direitos difusos, coletivos e individuais homogêneos .......................................................................65

3.3 Da Importância de se reconhecer os direitos e interesses difusos, no caso do autismo, para eficiência do julgado.

4 O controle jurisdicional de políticas públicas relacionadas ao autismo no Estado do Rio Grande do Norte ..67

5 Conclusões

Direito À SAÚde, POLÍticas PÚblicas E PORTADORES DE TRANSTORNO MENTAL: A INTERNAÇÃo COMPULSÓRIA DO DEPENDENTE QUÍMICO NO MUNICÍPIO DO RIO DE JANEIRO ....................................... 72

Emerson Affonso da Costa Moura

Laila Rainho de Oliveira

1 Introdução 72

$2 \mathrm{O}$ direito à saúde e as políticas públicas. 73

$3 \mathrm{O}$ dependente químico e a política pública de internação ..............................................................78

4 Estudo de caso: a internação compulsória no rio de janeiro.................................................................8

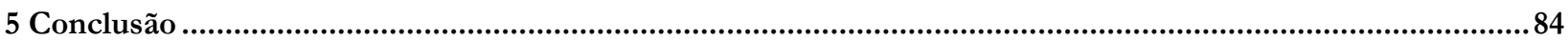

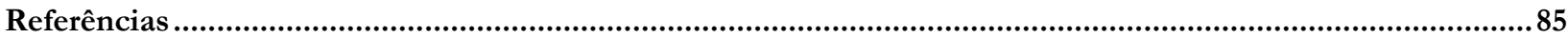

Produção de alimentos: agricultura familiar x Cultura de EXPortação no Brasil, SOB a PERSPECTIVA DA SUSTENTABILIDADE

Luá Cristine Siqueira Reis

João da Cruz Gonçalves Neto

1 Introdução .90

2 Agricultura familiar no contexto contemporâneo...................................................................................90

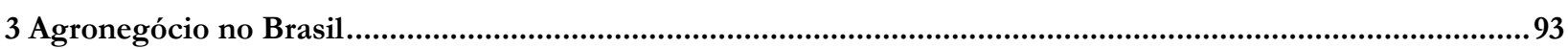

4 Reforma agrária, produção de alimentos e sustentabilidade ................................................................94

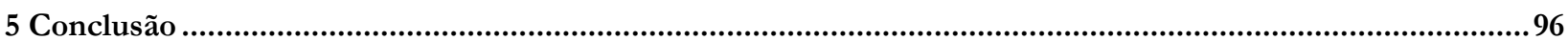

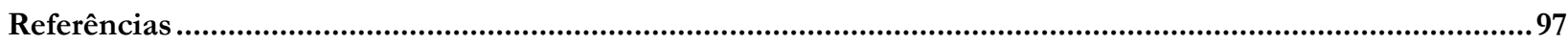

Direito AGROALIMENTAR E TERritório: REFLEXões SOBRE O USO DA ÁGUA NA ATIVIDADE AGRÍCOLA.100 Rodolfo Franco

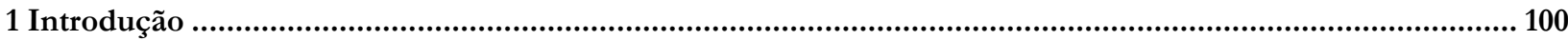

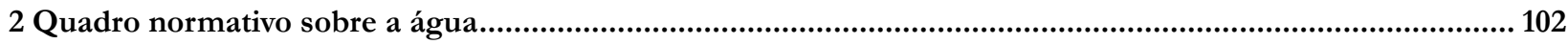

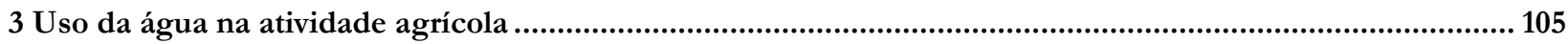

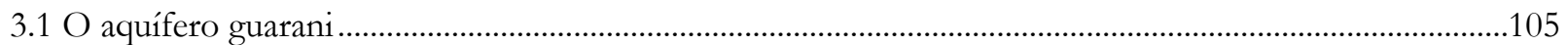

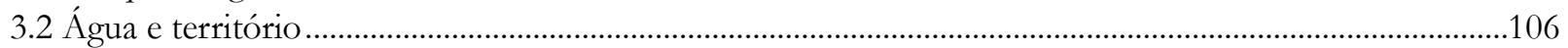

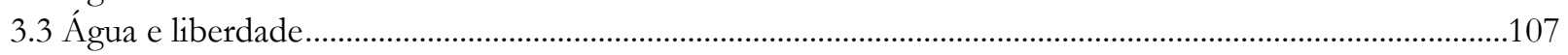

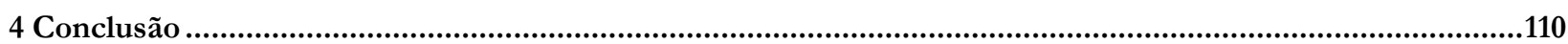

A construção de novas políticas sociais: o caso de Mato Grosso do Sul .............................114

Ricardo Luz Chagas Amorim

1 Introdução . .114

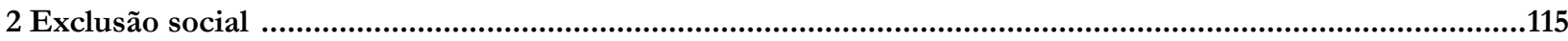

3 As dificuldades dos anos 1990 e a nova política social sul-mato-grossenses.............................................118

4 COGEPS e a gestão matricial das políticas sociais ........................................................................ 122

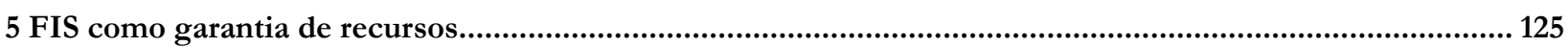




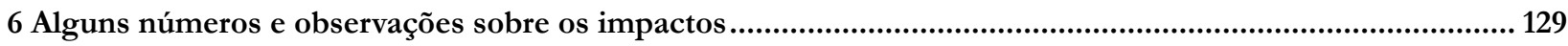

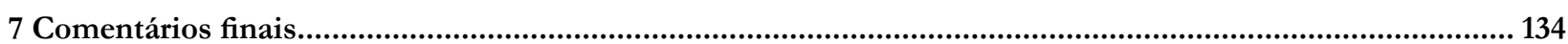

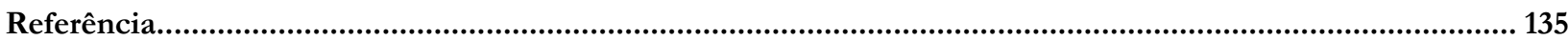

Programas sociais brasileiros e sua relação com a POBreza, A desigualdade e o desenvolviMENTO

Mirian Aparecida Rocha

Rosa Maria Olivera Fontes

Leonardo Bornacki de Mattos

Jader Fernandes Cirino

1 Introdução

2 Estudo sobre as inter-relações entre programas sociais, pobreza e desigualdade ...................................... 140

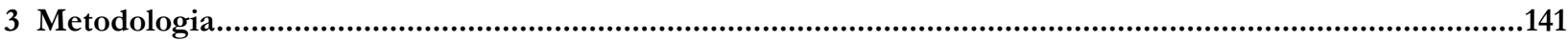

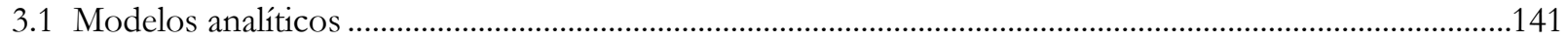

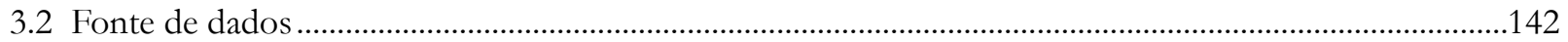

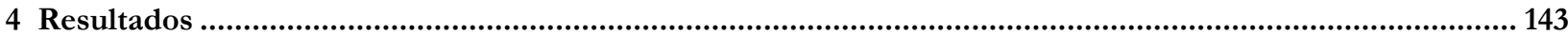

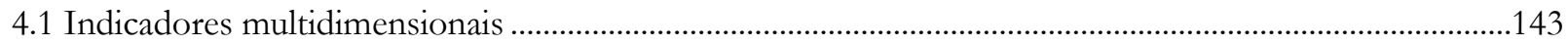

4.2 Comportamento dos indicadores multidimensionais nas regiões brasileiras .........................................145

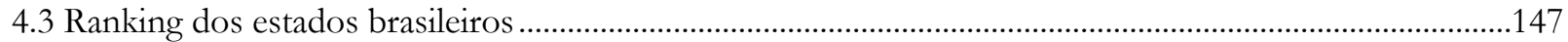

4.4 Impacto dos programas sociais sobre os indicadores multidimensionais..............................................148

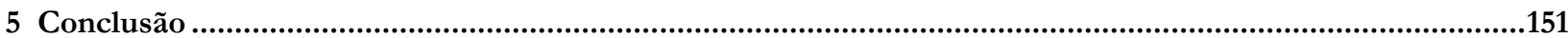

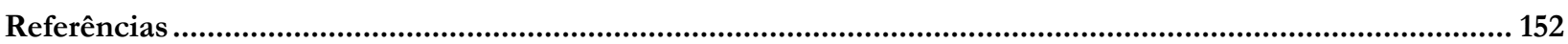

A JURISDiÇÃo CONSTITUCIONAL E A CONTEXTUALIZAÇÃo DO TEXTO DA CONSTITUIÇÃo FEDERAL DE

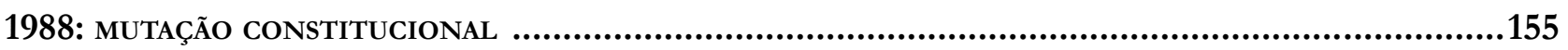

Eduardo Sadalla Bucci

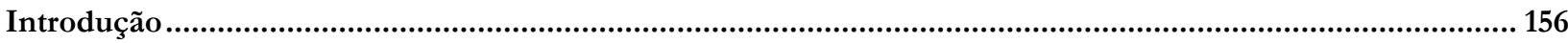

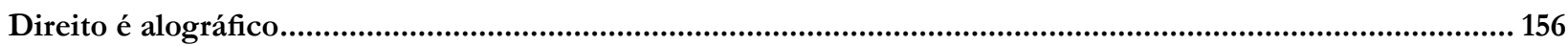

A jurisdição constitucional como fator de estabilização institucional ........................................................ 160

Mutação constitucional: poder reformador ou interpretação constitucional?................................................ 164

1. Mutação constitucional: delineação pela doutrina majoritária................................................................. 166

2. Mutação constitucional à luz de o direito ser alográfico: mudança das normas e não do texto constitucional ..... 167

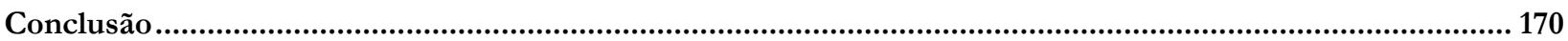

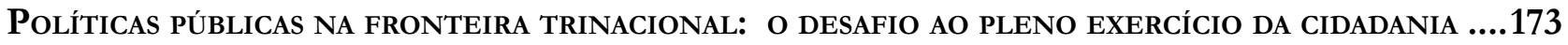

Priscila Lini

REPRESENTAÇÃO INTERVENTIVA, JURISDIÇÃO CONSTITUCIONAL E CONFLITO FEDERATIVO

Marcelo Rodrigues Mazzei

Sebastião Sérgio Silveira

Henrique Parisi Pazeto

Introdução

Aspectos gerais da intervenção federal

Histórico da representação interventiva no Brasil....................................................................... 190

A representação interventiva na Constituição Federal de 1988 ...................................................................191

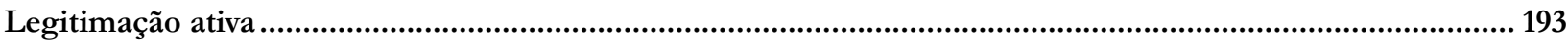

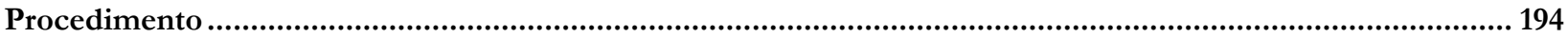


Decisão

Conclusão.

Referências

A LiCitaÇÃo PÚblica COMO INSTRUMENTO DE DESENVOLVIMENTO NA PERSPECTIVA DO PATERNALISMO LIBERTÁRIO.

Felipe Furtado Ferreira

Eduardo Carlos Pottumati

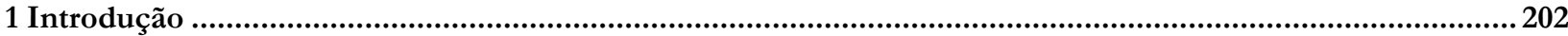

2 A licitação pública e sua função social .........................................................................................202

3 Direito ao desenvolvimento sustentável ........................................................................................206

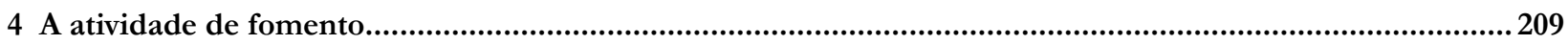

5 O paternalismo libertário como terceira via - simulitude com a atividade de fomento ..............................210

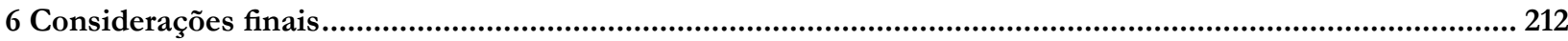

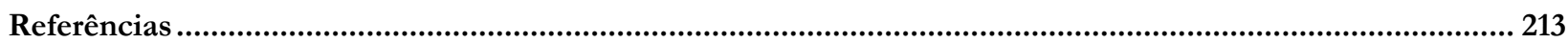

TributaÇÃo \& REgUlaÇÃO: UM DiAgnÓSTICO SOBRE INTER-RELAÇÕES POSSÍVEIS...........................215

Veyzon Campos Muniz

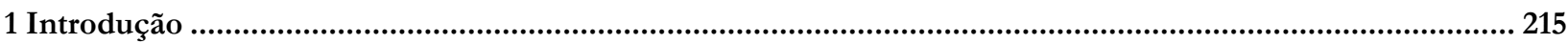

1.1 Um necessário acordo semântico ao tratar de regulação....................................................................216

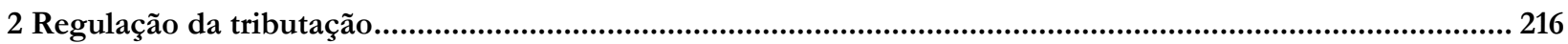

2.1 Apatia endêmica e a produção legislativa tributária...............................................................................217

3 Tributação como regulação........................................................................................................218

3.1 Medidas extrafiscais: um instrumento regulatório ............................................................................218

3.2 Automatismo moral e a análise de impacto regulatório........................................................................220

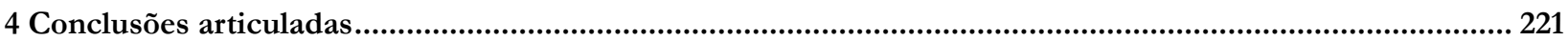

ANÁlISE ECONÔMICA DO DIREITO: A EFICIÊNCIA DA NORMA JURÍDICA NA PREVENÇÃO E REPARAÇÃo DE DANOS SOFRIDOS PELO CONSUMIDOR..................................................................................224

Héctor Valverde Santana

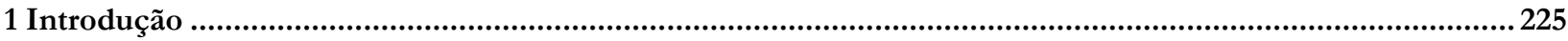

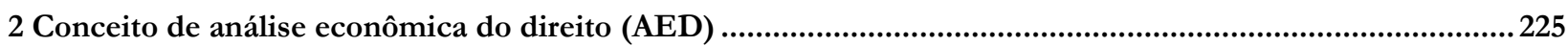

3 Eficiência das normas jurídicas protetivas do consumidor ..............................................................227

4 Análise econômica da prevenção e reparação de danos sofridos pelo consumidor ......................................228

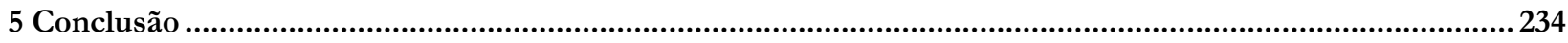

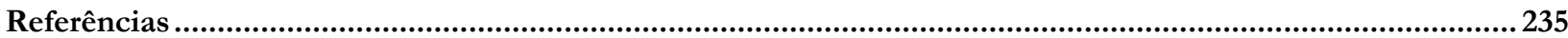

INOVAÇÃo PARA QUEM? O CASO DA POLÍTICA DE INOVAÇão dA UNIVERSIDADE FEDERAL DE JUIZ DE FORA

Marcos Vinício Chein Feres

Marcelo Castro Cunha Filho

1 Introdução

2 Integridade e ação comunicativa aplicada ao direito ......................................................................240

3 A busca pelo desenvolvimento tecnológico e sua repercussão na ICT federal de juiz de fora .....................244

4 Por que o direito não concorda com uma política inovação utilitária? A deficiência da política da UFJF .....249 
A Ponderação como Mecanismo de Solução de Conflitos entre Princípios Norteadores do Direito Penal Ambiental

Maria Isabel Esteves de Alcântara

Michelle Lucas Cardoso Balbino

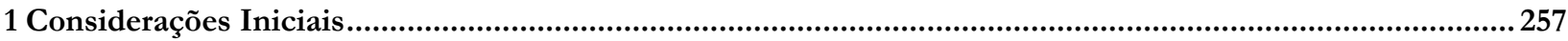

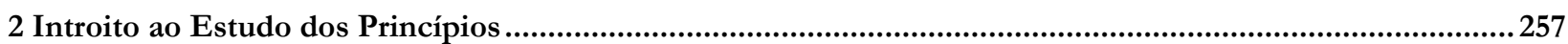

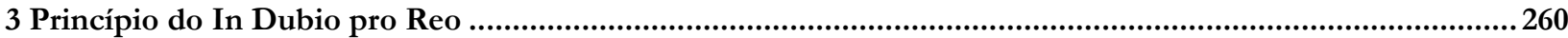

4 Princípio do In Dubio pro Ambiente ou In Dubio Pro Nature...................................................................... 261

5 A Ponderação como Mecanismo de Solução de Conflitos: Princípio "In Dubio pro Reo" Versus Princípio

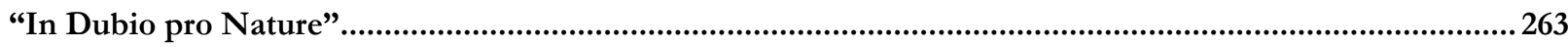

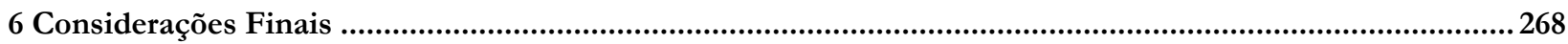

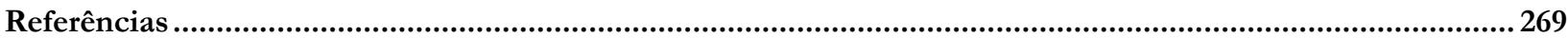

A NeCESSIDADE DE POLÍtiticas PÚBLICAS AMBIENTAIS MUNICIPAIS E PARTICIPAÇÃo POPULAR PARA COIBIR

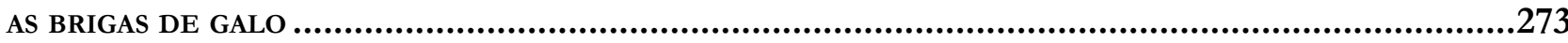

Marco Lunardi Escobar

Lucia Santana de Freitas

Gesinaldo Ataíde Candido

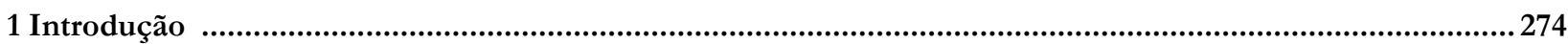

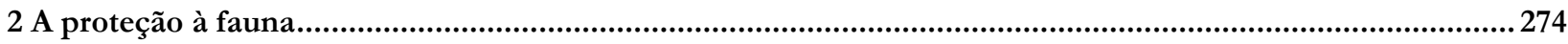

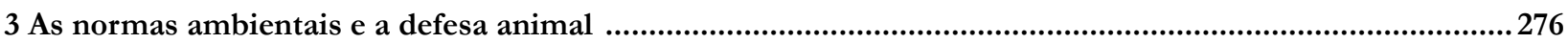

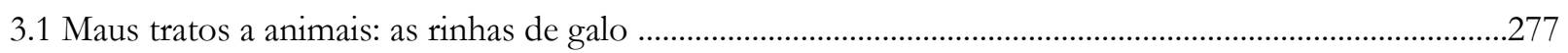

3.2 A competência do município em matéria ambiental e a necessidade de políticas públicas para coibir as

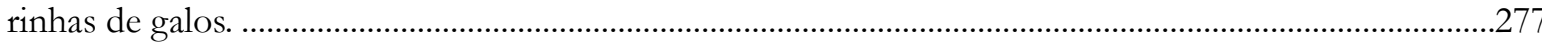

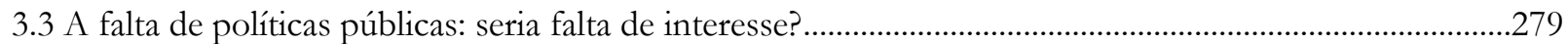

3.4 A participação da sociedade civil como auxiliar na gestão ambiental...........................................................279

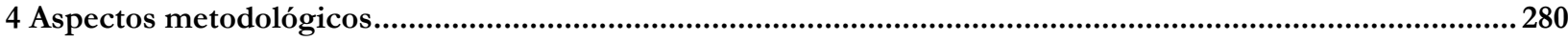

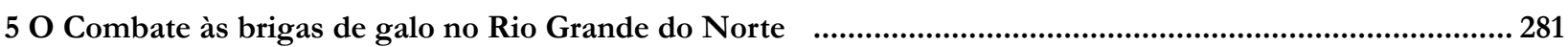

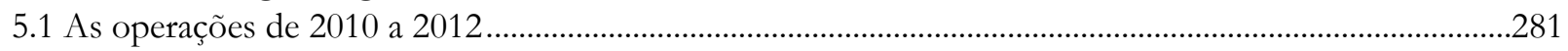

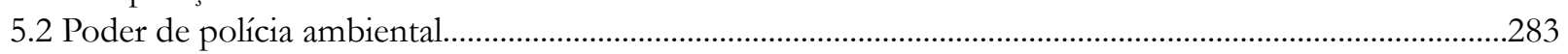

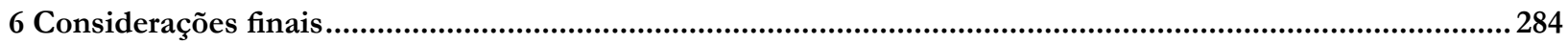




\title{
A construção de novas políticas sociais: o caso de Mato Grosso do Sul
}

\author{
The construction of new social policies: the case of \\ Mato Grosso do Sul
}

Ricardo Luz Chagas Amorim*

\section{Resumo}

O Brasil possui uma história de "departamentalização" da intervenção governamental, especialmente na área social. Os estudos conhecidos falam de baixa eficácia e dificuldade no rompimento do ciclo da pobreza. $\mathrm{Na}$ década passada, porém, surgiram inovações que constituíram um esforço importante para reconfigurar o marco institucional das ações sociais públicas. O presente trabalho discute uma dessas experiências: o caso do sul-mato-grossense. Ali, um arranjo organizacional diferente criou um novo modelo que só permitia avançar os gastos sociais se houvesse um plano de integração entre projetos. Ao longo do texto, são apresentadas as principais inovações implantadas nesse estado no início dos anos 2000 e, ao final, procura-se avaliar os impactos desse novo modelo de gestão de políticas sociais. Conclui-se que, apesar do avanço representado pela experiência, os resultados mostraram-se aquém do esperado.

Palavras-chave: Políticas sociais. Verticalização. Exclusão social. Coordenação e gestão.

\section{Abstract}

Brazil has a history of "departmentalization" of government intervention, especially in the social area. Studies acquaintances speak of low efficiency and difficulty in breaking the cycle of poverty. In the past decade, however, there were innovations which constituted a important effort to reconfigure the institutional framework of the social public actions. This paper discusses one of that experiences: the Mato Grosso do Sul. There, a different organizational arrangement created a new model that allowed advance social spending only if there was a plan of integration among projects. The text presents the key innovations implemented in the state in the early 2000 s and, finally, attempts to assess the impacts of this new management model of social policies. The conclusion shows that, despite the progress represented by the experience, the results proved to be less than expected.

Keywords: Social policies. Vertical integration. Social exclusion. Coordination and Management

\section{Introdução}

O Brasil, ao longo do século passado, construiu um padrão de políticas públicas marcado pela setorialização e departamentalização da intervenção 
governamental, especialmente na área social. Seus resultados eram conhecidos em termos da baixa eficácia e, sobretudo, da dificuldade de romper com o ciclo estrutural da pobreza. Mais recentemente, porém, marcadamente após a Constituição de 1988, percebeu-se o fortalecimento da preocupação social e uma renovação dessas políticas nas três esferas de governo. Foi, por exemplo, nos anos 1990, que ganharam importância os programas federais de transferência de renda e a aplicação de vários direitos chancelados pela Constituição de 1988. Os resultados promissores destes programas chegaram aos anos 2000 constituindo a face mais visível dos esforços do Governo Federal em favor da redução da pobreza extrema e da redução da desigualdade social brasileira.

Todavia, foi ainda no final dos anos 1990, com as dificuldades geradas pelas políticas econômicas de corte neoliberal e com as transformações da relação entre Estado e sociedade, que se observou interessantes reações de governos municipais e estaduais, no sentido de contornar a falta de recursos e reconfigurar o marco institucional das políticas públicas na área social.

Uma experiência bastante interessante aconteceu no estado de Mato Grosso do Sul. Ali, um arranjo institucional inovador, somado à priorização da integração das ações do governo, criaram um modo de agir do poder executivo estadual que só permitia avançar gastos em habitação, educação e seguridade social desde que houvesse, antecipadamente, um plano de integração entre os diferentes programas e órgãos da área social do estado.

Este estudo discute exatamente essa experiência sul-mato-grossense, destacando as principais inovações implantadas nesse estado no início dos anos 2000. Para tanto, o artigo está dividido em seis seções além desta introdução. Inicialmente, discute-se a problemática e o conceito de exclusão social, foco da atuação das políticas sociais. Em seguida, é apresentado o projeto, o conjunto das ações inovadoras implantadas pelo governo estadual. A seção três faz uma análise pormenorizada de um dos principais avanços levados a cabo nesse estado: o Conselho de Gestão das Políticas Públicas. Na quarta seção, apresenta-se a forma encontrada pelo poder executivo sul mato-grossense para garantir legalmente os recursos financeiros necessários ao andamento das ações. Na penúltima seção, são analisados alguns números da problemática social sul-mato-grossense, tentando avaliar o impacto das inovações vividas nesse estado. Por fim, são realizados alguns comentários sobre a importância do aprendizado representado pela experiência de Mato Grosso do Sul.

Assim, para começar a discussão, é preciso esclarecer sobre qual problemática atuam as políticas em foco. Ou seja, é preciso esclarecer o que se entende aqui por exclusão social.

\section{Exclusão social}

É automática a associação do vocábulo “exclusão” à noção de desigualdade. Não há como pensar em grupos carentes de direitos considerados básicos sem que se tenha em mente um comparativo, cujo acesso a esses direitos seja pleno. A desigualdade de renda, de oportunidade ao trabalho, de acesso à saúde, à justiça, à escola, à cultura, ao lazer, à segurança, à escolha e à cidadania política constitui, cada uma delas, faces de uma única questão abrangente que, quando estudada em conjunto e focada sobre os que estão despojados desses direitos costuma chamar-se de exclusão social ${ }^{1}$.

A questão se coloca, portanto, em patamar diferente do habitual: a exclusão social que realmente importa não se refere ao indivíduo, suas opções ou fraquezas naturais, e, sim, a grupos e as diferentes formas históricas encontradas pelos povos para construírem suas sociedades. Tais formas não foram, obviamente, consensuadas. Por vezes, sequer alcançadas pacificamente. Travaram-se lutas políticas entre indivíduos, grupos e classes, verteram-se rios de sangue, traiu-se e cooptou-se quantas vezes se pode o interesse do oponente.

1 POCHMANN, Marcio; AMORIM, Ricardo L. C. (Org.). Atlas da exclusão social no Brasil. São Paulo: Cortez, 2002. 
Por exemplo, se a agricultura e a metalurgia foram para Rosseau ${ }^{2}$, no Discurso sobre a desigualdade entre os homens, ao assentar a propriedade privada, as molas que engendraram na sociedade uma desigualdade crescente, é pouco provável, no entanto, como diz o próprio filósofo, que isso se fizesse sem o estabelecimento de leis e costumes capazes de legitimar a posse privada e, desse modo, excludente. Foi necessário, então, que se instituísse Estados capazes de regular as relações entre homens, grupos e classes, não só do ponto de vista da manutenção da propriedade, mas também das relações de produção que se estabeleceram a partir dela.

No Brasil, as diversas formas de desigualdade sempre foram tão gritantes que o país só parece inteligível por meio de dualidades. O desconcerto entre a pobreza contemporânea, numerosa e bárbara, e a imagem de uma nação que se quer cosmopolita e moderna, revela o quanto a sociedade brasileira ainda está distante de vencer a exclusão. Por conta disso, houve um esgarçamento tal do tecido social, marcadamente devido à desigualdade, que alguns se perguntaram se já não se havia ultrapassado as fronteiras da vida civilizada ${ }^{3}$.

Mas por que há tantos pobres no país? No passado, pensadores latino-americanos, ligados à CEPAL, tentaram responder a essa questão fundamental. Para eles, a forma como se organizou a produção na América Latina, após a colonização, levou à constituição de estruturas produtivas voltadas à exportação de produtos primários que não tinham como crescer a taxas necessárias para absorver a enorme parcela da população que vegetava no setor de subsistência.

Por essa via, mesmo os trabalhadores do setor exportador (moderno) viam seus salários constantemente pressionados pela mão-de-obra desejosa de emigrar do setor tradicional para o moderno. Desse modo, para os cepalinos clássicos, aos países latino-americanos restava como única alternativa a industrialização. Somente ela seria capaz de, alterando a estrutura econômica, vencer os limites impostos pelo modelo primário exportador ${ }^{4}$.

O fato de alguns países da região alcançarem significativo grau de industrialização sem, contudo, resolver os problemas da desigualdade e da pobreza, levou a própria CEPAL a criticar e repensar suas hipóteses. Todavia, apesar do rigor e relevância da análise desses pensadores, alguns exemplos históricos levam Oliveira e Henrique a afirmar que:

“[...] não se pode analisar a questão da pobreza simplesmente considerando-se a especificidade da estrutura econômica. $\mathrm{Na}$ verdade, os processos políticos, a maior ou menor presença dos interesses das camadas subalternas na atuação do Estado, constituem momentos necessários na análise dos determinantes da pobreza." ${ }^{5}$

Assim, não se pode considerar que a expressiva presença de pobres no Brasil seja causada tão-somente por um suposto baixo grau de desenvolvimento econômico. Basta lembrar que o país, especialmente, apresentou grande crescimento econômico no pós-guerra, o que o habilitaria a obter melhora generalizada no padrão de vida de sua população. No entanto, o que se vê, confirmado no estudo Atlas da Exclusão Social no Brasil, é que, de maneira geral, além de a pobreza continuar a ser muito grande no Brasil, ainda concentra-se em determinadas regiões e nas grandes cidades ${ }^{6}$.

Quais seriam, então, as causas? Segundo Oliveira e Henrique, durante o período de expansão econômica, entre 1930 e 1980 - industrialização com forte urbanização -, três seriam os eixos

2 ROUSSEAU, J. J. Discurso sobre a origem e os fundamentos da desigualdade entre os Homens. São Paulo: Abril, 1973.

3 TELLES, Vera. Direitos sociais (afinal do que se trata?). Belo Horizonte: UFMG, 2001.

4 Para uma discussão sobre a CEPAL, ver RODRÍGUEZ, Octavio. O Estruturalismo Latino-Americano. Rio de Janeiro: Civilização Brasileira, 2009.

5 OLIVEIRA, Carlos; HENRIQUE, Wilnes. Determinantes da Pobreza no Brasil: um roteiro de estudo. São Paulo em Perspectiva, v.4, n.2, abr./jun. 1990. p. 7.

6 POCHMANN, Marcio; AMORIM, Ricardo L. C. (Org.). Atlas da exclusão social no Brasil. São Paulo: Cortez, 2002. 
explicativos: a manutenção de uma estrutura agrária dominada pela grande propriedade, a fraqueza dos trabalhadores e de suas organizações no mercado de trabalho e, por fim, a cultura clientelista das políticas sociais implementadas no Brasil?.

$\mathrm{Na}$ agricultura, se houve importante crescimento da produção e da produtividade, não se superou a concentração da propriedade da terra, impedindo a democratização da posse no campo. Isso, somado às barreiras, à criação de sindicatos de trabalhadores rurais, à superexploração da mão-de-obra e à ausência de políticas sociais levaram a baixos padrões de vida da população rural. Como resultado, observou-se no Brasil um êxodo em direção às grandes cidades sem paralelo na história, capaz de, em poucas décadas, inverter a participação do meio urbano na população brasileira ${ }^{8}$.

As massas que a partir de então se acumularam nas cidades não poderiam, apesar do forte crescimento industrial, ser absorvidas no mercado formal de trabalho. Logo, esse contingente populacional passou a viver na informalidade e suas atividades precárias abocanhavam parcela pequena da renda gerada pelo setor moderno em expansão.

Todavia, se essa massa exerceu alguma pressão sobre os salários urbanos de base, talvez mais importante tenha sido a impossibilidade de os ganhos do trabalho no Brasil acompanharem o crescimento da produtividade, mesmo no setor moderno. A repressão aos movimentos organizados dos trabalhadores no país vem de longa data e continuou recentemente até pelo menos o fim da ditadura militar. Nesse último período, não só se viu a punição dos que ousavam reivindicar, mas também a instituição de uma política salarial com viés claro no sentido do arrocho na renda dos que vivem da venda de suas horas de trabalho. Com tudo isso, as grandes cidades passaram, crescentemente, a concentrar a pobreza do país?

Por outro lado, as políticas sociais que poderiam esmaecer à gritante desigualdade de renda não foram adequadas. Ainda sob a ótica de Oliveira e Henrique ${ }^{10}$, antes de 1964, o Estado brasileiro pouco fez nessa área. A partir daí, atuou de forma não compensatória, pois financiou várias políticas por meio das contribuições sociais pagas pelos próprios trabalhadores e, mais ainda, limitou o uso dos recursos, pois parte importante deles foi encaminhada para estimular o crescimento econômico ${ }^{11}$.

Em resumo, o Brasil manteve, durante o ciclo de expansão econômica de 1930/1980, uma situação social escandalosa e isso pouco tem a ver com os indicadores de sempre: baixo nível de escolaridade, analfabetismo, famílias numerosas, migração, etc. Essas características clássicas da pobreza são, na verdade, sintomas, consequências da ausência de reformas no campo, da ação do Estado e da fraqueza dos movimentos trabalhistas. Ou seja, o país evitou fazer as reformas devidas do capitalismo contemporâneo (agrária, social e tributária), empurrando a solução dos conflitos para saída do crescimento econômico.

Para piorar o quadro, no período posterior a 1980, o Brasil afastou-se do crescimento econômico, agravando os problemas sociais e, sobretudo, criando o que parecia ser uma nova exclusão. Em outras

7 OLIVEIRA, Carlos; HENRIQUE, Wilnes. Determinantes da Pobreza no Brasil: um roteiro de estudo. São Paulo em Perspectiva, v.4, n.2, abr./jun. 1990.

8 Bastaram quatro décadas para isso acontecer. Ver OLIVEIRA, Carlos e HENRIQUE, Wilnes. Determinantes da Pobreza no Brasil: um roteiro de estudo. São Paulo em Perspectiva, v.4, n.2, abr./jun. 1990.

9 É importante ter claro que esse período, apesar dos problemas discutidos, também foi marcado por significativa mobilidade social ascendente. Tanto dos trabalhadores que se tornaram empregados nas empresas do setor moderno como daqueles ocupados nas empresas que surgiram da acelerada dinâmica econômica desses anos.

10 OLIVEIRA, Carlos; HENRIQUE, Wilnes. Determinantes da Pobreza no Brasil: um roteiro de estudo. São Paulo em Perspectiva, v.4, n.2, abr./jun. 1990.

11 Tudo isso sem contar a lógica dos interesses privados envolvidos: fornecedores de insumos, empreiteiros, agentes financeiros, etc. Ver OLIVEIRA, Carlos; HENRIQUE, Wilnes. Determinantes da Pobreza no Brasil: um roteiro de estudo. São Paulo em Perspectiva, v.4, n.2, abr./ jun. 1990. É fundamental ainda ter em mente que pouca foi à participação da população na construção das políticas sociais levadas a cabo no país. Esta realidade é capaz de explicar boa parte da fragilidade das políticas sociais brasileiras. Ver CARVALHO, José M. A Cidadania no Brasil: o longo caminho. Rio de Janeiro: Civilização Brasileira, 2001. 
palavras, as políticas de corte neoliberal implantadas nos anos $1990^{12}$, ao impactarem fortemente a economia do país, geraram um novo contingente de excluídos, mas de perfil diferente do tradicional. Se antes a população excluída geralmente possuía baixa escolaridade, vinha de famílias numerosas, era migrante e tinha ocupação mal remunerada, a partir da segunda metade dos 1990 até o início dos 2000, o novo grupo que caminhava a passos largos para a exclusão era composto por pessoas alfabetizadas, com alguma escolaridade, vindos de famílias pequenas, já cidadãs urbanas, mas, e aqui a diferença, desempregadas ${ }^{13}$. Em outras palavras, sem vencer a antiga forma de exclusão social, agregou-se, naqueles anos, devido à quase ausência de crescimento econômico, uma nova leva de pessoas sem acesso a direitos sociais básicos, principalmente uma ocupação digna e segurança.

O resultado, então observado, indica que a lógica política perpassa necessariamente as possibilidades de enfrentamento da pobreza. Logo, para vencer essa cruel realidade é necessário que os trabalhadores e os mais carentes consigam representar seus interesses no debate e nos rumos do país. Quando isso ocorre, chega-se ao patamar de possibilidades necessárias para o decisivo avanço nas políticas públicas, marcadamente as sociais.

\section{As dificuldades dos anos 1990 e a nova política social sul-mato-grossenses}

As mudanças econômicas apenas aludidas anteriormente são, em grande medida, parte de um amplo processo de transformação por que passou a sociedade brasileira nas décadas de 1980 e 1990. Dentro dessas mudanças, o Estado surgiu mais uma vez no centro das atenções, pois foi sobre ele que se fizeram grande parte dos ajustes marcadamente a partir dos anos 1990.

Tais mudanças refletiram, além da crise iniciada nos anos 1980, uma pressão internacional em favor de uma reestruturação das relações entre Estado e sociedade na América Latina, cujo teor começa a se desenhar durante a crise do Estado Keynesiano ${ }^{14}$. A partir de então, no Brasil, a intervenção do Estado na economia e sua atuação em larga escala foram cada vez mais associados, pelos conservadores, como as causas dos problemas de baixo crescimento e aceleração dos preços que conduziram à crescente insatisfação social. Ao mesmo tempo, era claro, aos progressistas, que o importantíssimo crescimento econômico conseguido pelo Brasil desde 1930 tinha sido, por outro lado, francamente excludente e concentrador, deixando parcela significativa da população fora dos frutos do progresso produtivo do país ${ }^{15}$.

Assim, quando as políticas neoliberais da década de 1990 empreenderam o desmonte daquele Estado, poucas foram as vozes de protesto. Em termos específicos, porém, as reformas levadas a cabo naqueles anos não conduziram a ganhos significativos de eficiência e eficácia na atuação do Estado sobre a pobreza e a desigualdade do país.

Pode-se mesmo dizer que o problema foi apenas mudado de lugar. Se antes o Estado fora acusado de gigantismo, agora, a perigosa — porque vaga — ideia de "Estado necessário" reduzia o papel deste na economia e transformava sua atuação sobre os problemas sociais em todas as esferas de governo. Em outras palavras, sob o argumento do equilíbrio das contas públicas, bradava-se a fim de impedir que ações de maior envergadura se realizassem. Por isso mesmo, naquele momento, a Constituição de 1988 foi a maior defesa contra o desmonte da proteção social, obrigando os governos a gastar percentuais de arrecadação em áreas específicas como educação e saúde ${ }^{16}$.

12 FILGUEIRAS, Luiz. História do Plano Real: fundamentos, impactos e contradições. São Paulo: Boitempo, 2000.

13 POCHMANN, Marcio. (Org.). Desenvolvimento, trabalbo e solidariedade. São Paulo: Cortez e Fund. Perseu Abramo, 2002.

14 FREEMAN, Chris; LOUÇÃ, Francisco. As Time Goes By. Oxford: Oxford University Press, 2001.

15 FURTADO, Celso. O mito do desenvolvimento econômico. São Paulo: Paz e Terra, 1974.

16 AMORIM, Ricardo L. C. CF/88: economia e sociedade no Brasil. In: CARDOSO JUNIOR, José Celso. (Org.). A Constituição Federal de 1988 Revisitada. Brasília: Ipea, 2009.p. 9-33. v. 1. 
É preciso, inclusive, desmistificar um lugar comum no debate sobre os programas sociais, voltados aos mais pobres. A época era banal encontrar quem associasse os gastos sociais com despesas inevitáveis e moralmente defensáveis, mas que pesavam sobre o erário. Essa preocupação conduzia ao perigoso caminho da focalização dos programas de inclusão social que buscava, diziam seus defensores, aumentar a eficiência do dinheiro público empregado e a melhor atenção aos grupos mais vulneráveis da população. Não obstante, longe de defender os mais pobres, essa posição tendia a criar um descompromisso dos setores mais organizados da sociedade para com o destino dos menos abastados. Por quê? Primeiro, na visão simplista, bastaria oferecer uma cesta básica e mais alguns acessos à saúde para que os mais pobres fossem plenamente atendidos. Segundo, pelo motivo de, em momento algum, o discurso da focalização falar em oportunizar condições para que os homens e mulheres se tornassem cidadãos plenos de direitos e deveres, capazes de influir sobre o andamento e escolhas da sociedade. Terceiro, porquanto, ao desacreditar as políticas de caráter universal e afastar os grupos mais ricos do serviço público, surge o risco de lentamente sucatear os já escassos equipamentos públicos, afinal os setores sociais mais organizados se desinteressariam por sua manutenção.

Mas não é só isso. Os gastos dos programas de transferência de renda, revelaram-se, na verdade, bons investimentos sociais, com retornos interessantes inclusive aos cofres públicos. A figura 1, a seguir, demonstra essa lógica. Nela está descrito o fluxo dos recursos empregados em distribuição de fundos.

Figura 1 - Fluxo de recursos empregados em programas de transferência de renda

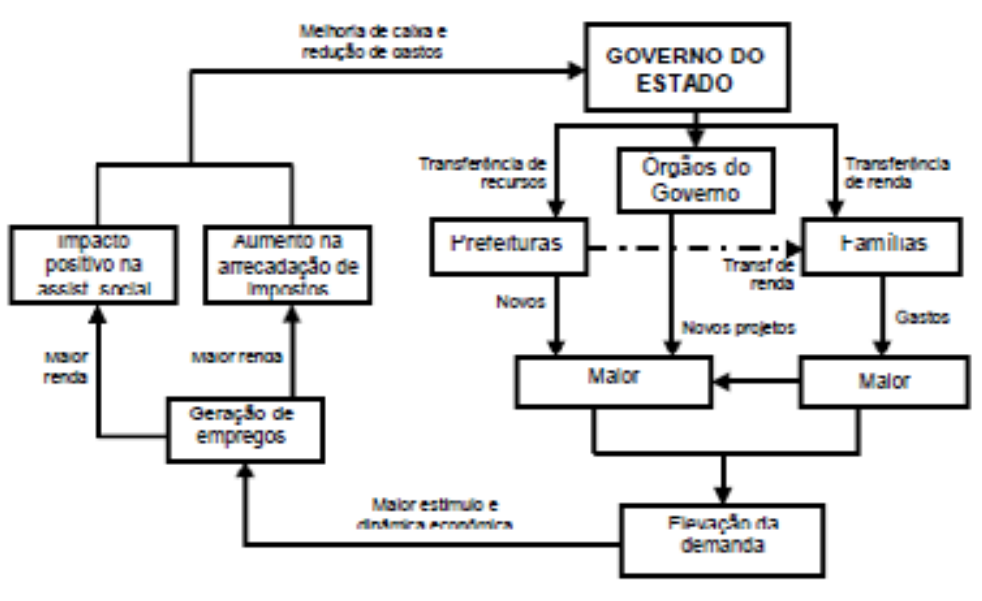

Fonte: Elaboração própria.

Dentro desse quadro, não deveria caber aos governos de qualquer esfera propor ou implantar políticas focalizadas de ação social. Entretanto, a estratégia liberalizante que guiava os discursos e muitas ações do Brasil da época, somado à crença em favor da focalização, longe da eficiência pretendida, lograram, na verdade, criar tanto um vácuo de projetos produtivo-econômicos como uma ausência de políticas sociais capazes de dar direção às ações do governo e evitar o "bater de cabeças" entre as diferentes áreas da administração pública. De outro modo, sem uma direção clara ou metas de longo prazo, principalmente na área social, o que se viu foram programas implementados por áreas diferentes, mas que atacavam os mesmos problemas, gerando sobreposição e desperdício de dinheiro público ${ }^{17}$.

Tudo isso sem contar com a fórmula de continuidade na implantação de programas que se caracterizavam pela verticalização das decisões e, dada a departamentalização de cada plano, pela pequena amplitude

17 BRASIL. Ministério do Desenvolvimento Social e Combate à Fome. Departamento de Prospecção para a Inclusão Produtiva. Acelerar a Inclusão Produtiva. Brasília: MDS, 2010. (Mímeo) 
de objetivos buscados ${ }^{18}$. Os resultados não poderiam ser outros: a tradicional ineficácia na solução dos problemas, ineficiência nos gastos, disputas políticas pessoais e assistencialismo.

As dificuldades crescem ainda mais quando se analisa o quadro econômico das unidades da federação. No caso específico do Mato Grosso do Sul, e mesmo na maioria dos estados, havia o grave problema da transferência de recursos em direção à União devido ao pagamento de dívidas contraídas despreocupadamente no passado. Naquele estado, essa transferência esvaziava os cofres públicos sem contrapartida pelo esforço fiscal realizado pelo seu governo que vinha apresentando superávits primários há alguns anos ${ }^{19}$. Para piorar, no final de 1998, próximo a posse do novo governador, os servidores do poder executivo estadual sofreram um atraso salarial de quatro meses e o repasse de recursos aos demais poderes também não estava em dia. Naturalmente, o dinheiro que sobrava para ser investido era pouco diante das enormes demandas sociais ou, em outras palavras, estava estabelecido o conflito entre a emergência e os projetos de maior prazo.

Dentro desse quadro caótico, agravado por um processo de forte crescimento do desemprego urbano e fechamento de indústrias, as políticas sociais estaduais seguiam a tradição do país: eram verticalizadas e não coordenadas entre ii $^{20}$. Havia, portanto, necessidade de inovação em termos de construção de políticas sociais a fim de contornar as dificuldades econômicas do estado. Foi naquele contexto, que o governo de Mato Grosso do Sul realizou, apesar das emergências encontradas e das dificuldades macroeconômicas, importantes mudanças na construção e na forma de gestão das políticas sociais ${ }^{21}$. Para começar, a urgência dos problemas e as dificuldades de orçamento deixavam claro que uma nova postura era necessária, caso houvesse a intenção de enfrentar os problemas sociais do estado.

De qualquer modo, fosse qual fosse a decisão, os gastos na área social não poderiam parar e significavam um volume importante de recursos aplicados pelo governo sul-mato-grossense. Já não era novidade, no entanto, que, como em todo país, as políticas sociais, locais ou não, eram verticalizadas, atacando, por meio de diferentes órgãos e ações, questões similares e, às vezes, até o mesmo problema. As áreas sem atenção, as sobreposições de ações e, principalmente, a ineficácia e timidez dos resultados eram evidentes. A ausência de planejamento e descoordenação entre equipes, programas, ações e gastos já havia ficado clara e a necessidade de superar tal situação era premente. A pergunta era: como fazê-lo?

A primeira e evidente resposta foi afastar a fragmentação presente nas políticas sociais do estado e, portanto, buscar articulação dos projetos, programas e ações já implantados e em construção. Mais precisamente, no âmbito das políticas sociais, era necessário absorver e aproveitar os impactos das ações e despesas do poder executivo, até então dispersos, articulando-os para que o resultado colaborasse sinergicamente para o enfrentamento dos problemas sociais. Em uma palavra: coordenação.

Para tanto, era necessário realizar a matricialidade das ações de enfrentamento da exclusão social, usando, para isso, prioridades bem estabelecidas em favor de um processo de superação da pobreza por meio de estruturas mais integradas e capazes de realizar mais com menos recursos. Mas continuava a pergunta: como fazer isso?

A resposta em favor da matricialidade e da integração foram buscadas por meio da construção de um Programa Integrado de Inclusão Social (PIS). Por meio deste instrumento criou-se a possibilidade real de integrar as normalmente verticalizadas políticas setoriais e desfragmentar o combate à exclusão tratando

18 ARANHA, Adriana V. (Org.). Fome Zero: uma história brasileira. Brasília: Ministério do Desenvolvimento Social e Combate à Fome, 2010. v. 2.

19 BLANES, Denise et al. Inclusão social: uma utopia possível. São Paulo: Cortez, 2006.

20 As percepções e afirmações que orientam os próximos três parágrafos são fruto das conversas e entrevistas realizadas com membros do corpo técnico do Governo do Estado do Mato Grosso do Sul durante o trabalho de pesquisa realizado em 2005/2006 Ver BLANES, D. et al. Inclusão social: uma utopia possivel. São Paulo: Cortez, 2006.

21 Para questões econômicas, ver AMORIM, Ricardo L. C. As diferentes dinâmicas regionais dentro da economia brasileira: o caso do Mato Grosso do Sul. Revista de Economia Mackenzie, São Paulo, v. 6, p. 113-148, 2008. 
o problema como uma totalidade. O discurso era claro: as ações do estado sobre as populações mais carentes não poderiam mais restringir-se apenas à transferência direta de renda e, sim, estar integradas na ampliação da cidadania desses grupos ${ }^{22}$. Desta forma, ficou claro que a transferência de renda deveria estar obrigatoriamente vinculada a programas de geração de renda e emprego, inclusive, de microcrédito ${ }^{23}$. Além disso, era preciso estimular os grupos atingidos por essas políticas para que conquistassem a crença em seus direitos e na sua participação social, isto é, na sua integração política. Tal confluência de esforços é a essência da matricialidade das políticas sociais públicas implementadas no Mato Grosso do Sul e em outros poucos lugares do país ${ }^{24}$.

A questão territorial aparece como outra importante característica, que associada à matricialidade ganha contornos inovadores também. O motivo está na possibilidade de criação de ações especiais direcionadas para áreas determinadas onde é possível somar políticas sociais de caráter universal e programas limitados àquela região.

A questão de gênero é outro recorte importante. Em Mato Grosso do Sul, o PIS colocou as mulheres como as principais responsáveis pelo lar e pelos filhos e, assim, salientou a necessidade de atendê-las prioritariamente dentro dos programas (moradia, saúde, transferência de renda, etc.). Foi uma atenção relevante e inovadora, pois, naqueles anos, percebeu-se o crescimento da pobreza feminina, inclusive, como chefe de família, no total de pobres do país.

Tratou-se, portanto, de uma estratégia de gestão desafiadora. A cultura de políticas sociais setorializadas e verticalizadas, tão arraigada à ação do Estado brasileiro e piorada pela ausência de planejamento e metas, tornou a ideia de matricialidade e integração objetivos só alcançáveis mediante o empenho das equipes encarregadas, o compromisso de participação das diferentes áreas envolvidas e, talvez mais importante de tudo, o empenho efetivo do mandatário do executivo e de seus escalões imediatos.

No caso específico de Mato Grosso do Sul, foi preciso reunir as mais diferentes secretarias e órgãos da administração, discutir sobre as questões enfrentadas parcialmente por cada um deles e entrar em consenso sobre a forma de atuação, prioridade e (por que não?) a distribuição do mérito ${ }^{25}$. Para tanto, a vontade do governador foi condição necessária. O empenho do mandatário e a criação de canais que permitissem recorrentes encontros e o fluir das decisões do grupo de secretários foi fundamental para o progresso da matricialidade na administração das ações públicas.

Quando esses canais foram criados e, no caso, o governador comprometeu-se fortemente com a ideia, o dia a dia da construção de políticas integradas de ação conjunta sobre a exclusão social tornou-se cada vez mais rotineiro e menos difícil, embora, obviamente, nunca tenha sido realmente fácil ${ }^{26}$. Tratava-se da criação de uma nova cultura dentro da máquina pública, marcadamente nos altos escalões, e novos processos demoram algum tempo para serem assimilados até tornarem-se norma/rotina.

22 CONSELHO DE GESTÃO ESTADUAL DE POLÍTICAS SOCIAIS (COGEPS). Fundo de Investimentos Sociais: combatendo a pobreza e promovendo a inclusão social. Campo Grande: Governo do Estado de Mato Grosso do Sul, 2002. (Manual de Orientação).

23 Entende-se por projeto social a aplicação de recursos em uma ação ou atividade que pretende transformar uma parcela da realidade, solucionando ou minorando um problema social específico. Por programa social depreende-se o conjunto de projetos sociais que atendem a população e perseguem objetivos comuns. Estes também são chamados de políticas setoriais por se concentrarem em áreas específicas da carência social, tais como saúde, educação, moradia, etc. O conjunto dos programas sociais forma a política social. Esta visa elevar a qualidade de vida da população em geral, ou seja, trata-se da estratégia adotada pelo poder público para atuar no enfretamento dos problemas sociais em suas diferentes formas e setores. Ver CONSELHO DE GESTÃO ESTADUAL DE POLÍTICAS SOCIAIS (COGEPS). Fundo de Investimentos Sociais: combatendo a pobreza e promovendo a inclusão social. Campo Grande: Governo do Estado de Mato Grosso do Sul, 2002. (Manual de Orientação).

24 Os exemplos mais famosos desse tipo de política social parecem ser os bastante estudados casos das prefeituras dos municípios de Santo André, São Paulo e, mais recentemente, Osasco.

25 É espinhoso o tema da distribuição do mérito sobre o sucesso de políticas dentro de um governo. Quando o assunto são políticas sociais, o problema fica ainda maior, pois além do prestígio, pode envolver interesses políticos pessoais de cada um dos participantes do poder executivo.

26 BLANES, Denise et al. Inclusão social: uma utopia possível. São Paulo: Cortez, 2006. 
Estava claro, no entanto, que para isso acontecer era preciso que existisse um caminho, um próximo passo, um plano, um “como chegar lá”? Foi na solução dessa questão que talvez o estado de Mato Grosso do Sul tenha inovado de maneira mais profunda: criou um conselho de alto nível, com assento de todos os secretários mais o Procurador-Geral do estado, para decidirem, juntos, a ação integrada de suas políticas e equipes. Mais, e, muito importante, o colegiado estava ligado diretamente ao Gabinete do Governador. Trata-se do Conselho de Gestão Estadual de Políticas Sociais (COGEPS).

O esforço, continuamente retrabalhado, de integração promovido pelo COGEPS resultou, por exemplo, na formalização do Programa Integrado de Inclusão Social, documento que instruía o COGEPS e demais órgãos ligados à questão da inclusão sobre as diretrizes que deveria seguiras ações do governo do estado nessa área a partir de então.

\section{COGEPS e a gestão matricial das políticas sociais}

A gestão matricial de políticas públicas, embora considerada uma meta positiva, é difícil de ser executada e, talvez, por isso, ainda pouco comum aos governos do país. De maneira geral, a cultura da política pública sustenta-se na especialização e no domínio sobre determinados nichos da atuação do Estado que só recentemente foram questionados.

Em tal ambiente, a experiência inovadora na gestão de políticas sociais introduzida pelo governo do estado de Mato Grosso do Sul, entre 1999 e 2006, deve ser observada com atenção. Na verdade, essa gestão não se sustentou em apenas um ato de inovação, mas, sim, em uma série de medidas originais que impactaram o diaa-dia da administração pública, o encaminhamento de políticas e o atendimento das demandas da sociedade.

Dentro desse conjunto, o elo mais importante em torno do qual circularam as diferentes medidas foi a criação do Conselho de Gestão Estadual de Políticas Públicas (COGEPS) ${ }^{27}$. Ali, já no decreto que o instituiu, justificou-se o papel intencionalmente inovador do órgão, ante uma realidade social adversa e agravada por políticas nacionais de corte neoliberal impostas durante os anos 1990. Nele, o executivo estadual afirmou:

Considerando a necessidade de o Governo do Estado desenvolver um Programa Integrado de Inclusão Social, para enfrentar os graves e complexos problemas sociais causados pelo desemprego, pela iníqua distribuição de renda, agravados pelos desacertos da política econômica neoliberal e pela histórica desarticulação dos programas sociais; Considerando que as políticas sociais devem articular-se no esforço global das políticas públicas, visando a elevar o patamar de qualidade de vida e dos índices de inclusão social, econômica, cultural e política da população em situação de pobreza. ${ }^{28}$

Em síntese, observava-se que perante os graves e históricos problemas do país, somados aos recentemente criados, o governo do estado anteviu a necessidade de criar uma política de inclusão social e que esta, dado o tamanho dos problemas e o entrelaçamento das carências dos mais pobres, deveria ser integrada tanto no intuito de atender os cidadãos em suas diferentes, mas convergentes, privações, quanto no sentido de tornar mais eficaz e eficiente o combate a essa aberta ferida brasileira.

Para tanto, na mesma seção do Decreto 9.825, fica explícita a intencionalidade de gerir tais políticas matricialmente e, portanto, de maneira inovadora. Diz o decreto mais à frente:

Considerando, finalmente, a necessidade de se constituir um órgão colegiado para propor, coordenar e acompanhar a implementação das políticas sociais, inserido num novo modelo de gestão democrática e participativa, apoiado nos princípios da universalidade, racionalidade e complementaridade. ${ }^{29}$

27 Criado pelo Decreto Estadual 9.825, de 25 de fevereiro de 2000 (D.O. 5.212, de 28/02/2000). A legislação que trata do COGEPS foi posteriormente modernizada e sofreu pequenas alterações.

28 Governo do Estado do Mato Grosso do Sul. Decreto n. ${ }^{\circ} 9.825$ de 25/02/2000.

29 Governo do Estado de Mato Grosso do Sul. Decreto n. ${ }^{\circ} 9.825$ de 25/02/2000. 
Portanto, não era outra a finalidade máxima do órgão que a articulação e integração das diferentes políticas sociais implementadas pelos diversos órgãos do governo estadual e a busca de sinergias entre as diferentes esferas de governo a fim de alcançar um patamar melhorado de atendimento, marcadamente ao cidadão carente.

A partir dessa missão, estabeleceram-se as funções para que o COGEPS cumprisse sua finalidade. Em resumo, destaca-se as cinco principais: a) articular de forma crescente as políticas sociais, inclusive ações intersetoriais e mesmo intergovernamentais, privilegiando o atendimento das necessidades sociais sobre o retorno econômico; b) definir e aprovar o PIS sul-mato-grossense, a partir das ações dos diversos setores do governo; c) apoiar a captação de recursos junto ao governo federal, organizações nacionais e internacionais; d) fomentar pesquisas que permitam melhor conhecer a exclusão social no estado, assim como possíveis alternativas de combate ao problema; e) avaliar as políticas e seus impactos no combate à exclusão social.

Para cumprir essas funções, o COGEPS era composto por 18 membros, sendo 11 secretários estaduais e o procurador-geral da defensoria pública ${ }^{30}$. Ou seja, nomes pertencentes ao primeiro escalão do governo do estadual e isso não era sem razão: tratava-se de gerar o comprometimento a partir dos centros de decisão mais importantes do poder executivo do Mato Grosso do Sul com a difícil tarefa de dessetorializar e desverticalizar as políticas públicas de impacto social. Os outros seis membros eram cidadãos sem vínculo com o executivo e nomeados pelo governador a partir de sua notória atuação no campo da inclusão social. O objetivo declarado era, naturalmente, elevar a participação direta da sociedade no debate, priorização e escolha das ações do estado sobre o tema.

O COGEPS possuía uma estrutura técnico-administrativa funcional e que foi melhorada desde a sua criação (Figura 2). Em 2006, o conselho compunha-se da Presidência, Vice-Presidência, Pleno, Secretaria-Executiva e Câmaras Técnicas. A Secretaria Executiva tinha sob sua responsabilidade a Coordenadoria Técnica e Jurídica que, por sua vez, comandava Assessoria Técnica-Política e o Apoio Administrativo.

Figura 2 - Estrutura e funcionamento do COGEPS

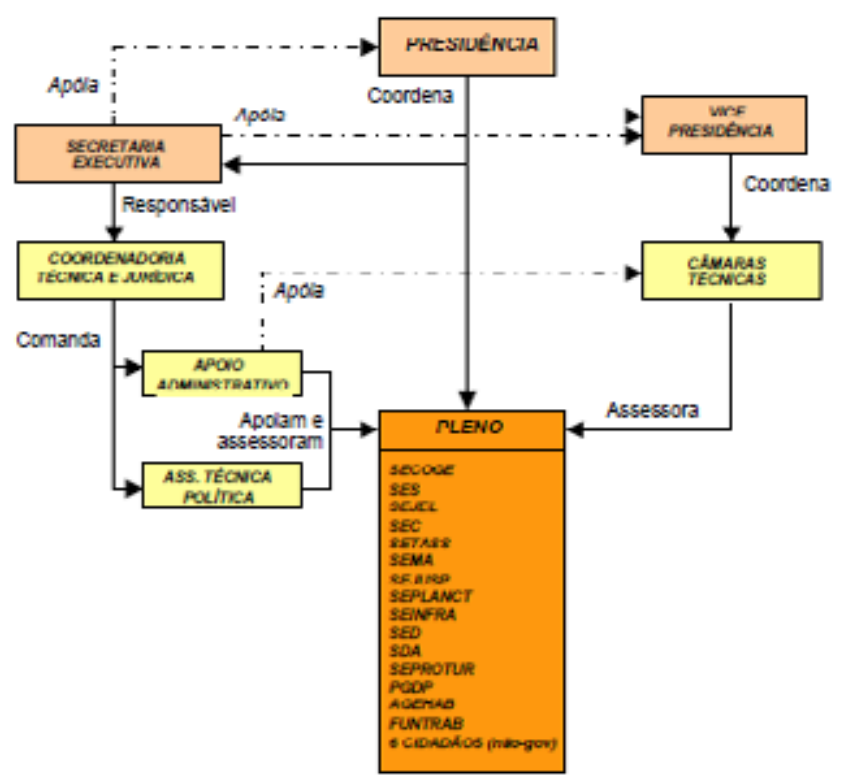

Fonte: Elaboração própria a partir do Regimento Interno.

30 São eles: Secretários de Estado de Coordenação-Geral do Governo, de Saúde, de Cultura, Esporte e Lazer, de Trabalho, Assistência Social e Economia Solidária, de Meio Ambiente, de Justiça e Segurança Pública, de Planejamento e de Ciência e Tecnologia, de Infraestrutura e Habitação, de Educação, de Desenvolvimento Agrário, da Produção e do Turismo e, o já citado, Procurador-Geral da Defensoria Pública. 
No caso da Presidência, que era uma escolha e nomeação do governador dentre os membros do conselho, a sua função básica referia-se a coordenação dos trabalhos do COGEPS, fazer cumprir suas deliberações e representar o chefe do executivo. Do mesmo modo, a Vice-Presidência também era uma escolha a cargo do governador e sua função básica implicava em coordenar as Câmaras Técnicas e substituir o presidente nas ocasiões que se fizesse necessário.

A Secretaria-Executiva era o último cargo nomeado pelo governador e sua atuação era fundamental para o bom andamento dos trabalhos. Cabia a ela apoiar e assessorar as Câmaras Técnicas, criar e manter um banco de dados dos projetos e programas ligados ao COGEPS, secretariar o conselho em sua rotina e dar encaminhamento às decisões.

As Câmaras Técnicas eram formadas por técnicos pertencentes aos órgãos que integravam o colegiado ou Pleno, acumulando funções. Tratava-se, portanto, de um setor de assessoramento, sem voto ou poder de decisão. Seu papel envolvia a difícil tarefa de elaborar o PIS, articulando as políticas e as ações do governo de acordo com a missão do COGEPS. Também estava sob sua responsabilidade o acompanhamento e a avaliação de implantação e de resultados dos programas.

Por fim, o órgão mais importante do conselho era o Pleno. Nele reuniam-se, uma vez por mês, todas as autoridades citadas anteriormente para debater e deliberar acerca de projetos, aprovar a aplicação de recursos, discutir e avaliar o andamento das ações e políticas e, finalmente, aprovar o Programa Integrado de Inclusão Social.

Esse conjunto funcionava de maneira muito interessante e a Figura 3 ajuda a esclarecer seu papel central. O COGEPS, como já foi dito, era o órgão que centralizava e definia a política social do estado de Mato Grosso do Sul. Era a partir dele e de suas decisões que os projetos, programas e gastos sociais tinham autorização e recursos para acontecerem. Para tanto, todo órgão do governo ou mesmo os membros e técnicos do conselho podiam encaminhar propostas e sugestões para compor a construção da atuação social do poder executivo.

Figura 3 - Fluxo dos projetos dentro do COGEPS

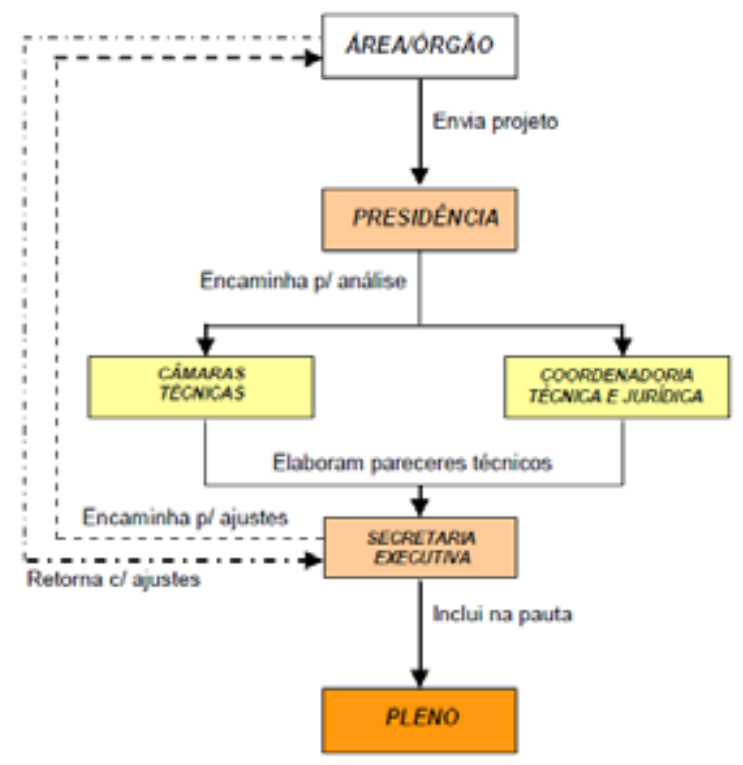

Fonte: Elaboração própria a partir do Regimento Interno.

Essas mesmas propostas que chegavam em busca de fundos eram analisadas e selecionadas a partir dos seguintes critérios básicos: a) ter nítido apelo social e de interesse público e, fundamentalmente, atender as prioridades da população; b) possuir metas e objetivos claramente definidos; c) identificar 
nitidamente o público alvo do projeto; d) especificar a territorialidade do projeto, isto é, sua abrangência geográfica; e) discriminar adequadamente custo total e analítico para realização do projeto; f) data de início e de fim do projeto explícitas. Além desses, os projetos, para serem aprovados, deveriam atender aos seguintes princípios/diretrizes: a) democratização da gestão, com a participação dos usuários em todas as fases do processo: formulação, execução, controle e avaliação; b) compromisso do órgão gestor e do executor com os direitos de cidadania; c) caráter público da ação, com a divulgação das atividades; d) cumprimento das leis e normas técnicas que regulamentam as políticas setoriais e de direitos; e) acesso e não-discriminação nas atenções sociais, de qualquer natureza; f) respeito à dignidade do cidadão, à sua autonomia, privacidade e à convivência familiar e societária; g) precedência da atenção à necessidade social sobre as exigências de rentabilidade econômica; h) complementaridade entre a rede estatal, de organizações da sociedade civil sem fins lucrativos, na prestação de serviços, afiançando o caráter público do atendimento; i) igualdade de oportunidade no acesso a bens e serviços ${ }^{31}$.

Desse modo, os projetos com tais características eram analisados pelo COGEPS por meio do Pleno, e, só após a aprovação e autorização do órgão, estavam aptos a receber os recursos necessários para sua realização. Ou seja, como já foi dito, o conselho era o órgão central da política social matricial implementada pelo governo sul-mato-grossense.

Tão importante, no entanto, quanto o poder de autorizar ou vetar o acesso de um projeto aos recursos, item fundamental de qualquer investimento, era a origem do dinheiro. Assim, parte do poder do COGEPS vinha exatamente de um fundo financeiro, criado em 2000, e que estava sob seus cuidados. Esse fundo, chamado FIS (Fundo de Investimento Social), estava voltado exclusivamente para a realização de investimentos sociais e permitiu ao governo angariar os recursos necessários para impulsionar programas considerados prioritários em um período de grave penúria do erário estadual. Foi esse conjunto, a existência de um fundo e sua vinculação ao COGEPS, que possibilitou a adoção de uma nova estratégia de combate à exclusão.

Tal poder, contudo, também gerou maior responsabilidade do colegiado. Afinal, além de construir a face da política social do estado, o COGEPS tinha também o papel de autorizar quais projetos considerados integrados com a estratégia de combate à exclusão receberiam recursos, tornando-se, desse modo, corresponsável pelo bom andamento dos projetos. Assim, ao COGEPS tornou-se necessário acompanhar e fiscalizar as contas dessas realizações. Embora fossem os executores dos programas e projetos, os responsáveis pela apresentação de relatórios e documentos que prestassem contas ao conselho, na forma da Lei Estadual n. $2.105^{32}$, era a esse último que cabia observar o correto gasto dos recursos do fundo.

Nesse sentido, o COGEPS, além de principal órgão garantidor da matricialidade das políticas sociais do governo do estado de Mato Grosso do Sul, desempenhou também funções de articulação, criação de instrumentos de gestão, fiscalização, regulamentação, celebração de acordos entre estado e municípios e também de órgão avalista para utilização dos recursos disponibilizados por meio de fundo de investimentos, especialmente criado para sustentar a realização de políticas sociais.

\section{FIS como garantia de recursos}

As tradicionais dificuldades orçamentárias do setor público brasileiro sempre trouxeram consigo um problema ainda mais grave do que o pagamento de dívidas financeiras: a dificuldade do Estado em atuar sobre a urgente pobreza e exclusão social presente em todo país.

31 CONSELHO DE GESTÃO ESTADUAL DE POLÍTICAS SOCIAIS (COGEPS). Subsídios para a realização do diagnóstico socioeconômico da efetividade das políticas públicas do governo de Mato Grosso do Sul. Campo Grande: Governo do Estado de Mato Grosso do Sul, [200?]. (mímeo).

32 Lei que institui o Fundo de Investimento Social (FIS), discutido na próxima seção. 
No caso do Mato Grosso do Sul, devido aos graves problemas do erário, não bastava ao governo melhorar a arrecadação e reduzir os gastos. Essas ações, embora realizadas com sucesso ao gerar anos de superávit primário ${ }^{33}$, não disponibilizavam recursos na quantidade necessária para os investimentos e programas urgentes ou essenciais para o crescimento econômico do estado. Ao mesmo tempo, os compromissos assumidos em gestões passadas com a União comprometeram um percentual fixo da arrecadação tributária estadual. Assim, as sobras fiscais eram em parte canalizados para o pagamento da dívida do Mato Grosso do Sul com o Governo Federal ${ }^{34}$.

Foi por esse motivo que surgiu a ideia de fundos voltados exclusivamente para as áreas onde a atuação do Estado era considerada mais urgente. Tais fundos formavam uma massa de recursos que não fazia parte do caixa do Tesouro estadual e que, por isso mesmo, não estava sujeita aos acordos firmados com a União e relativos ao erário. Desse modo, tratava-se de dinheiro "carimbado" (com destino certo), mas disponível para investimento ou gasto em programas de caráter predefinido. Assim, embora não sejam recursos de uso livre, permitiam ao poder executivo realizar ou dar continuidade a projetos que, por falta de espaço no orçamento, poderiam ser paralisados.

A legislação que regula esse tipo de fundo de recursos (Lei Federal n. 4.320 de 17/03/1964) afirma que este deve ter como características:

a) receitas e despesas especificadas pela entidade jurídica instituidora do fundo; b) vinculação legal dessas receitas aos objetivos específicos ou serviços; c) normas peculiares de aplicação dessas receitas; d) transferência para o exercício seguinte de saldo positivo apurado em balanço; e) normas peculiares de controle e prestação e tomada de contas; f) manutenção da competência específica para fiscalização do Tribunal de Contas; g) vinculação a um órgão integrante da estrutura administrativa da entidade jurídica. ${ }^{3}$

Nesses termos, o governo sul-mato-grossense inovou mais uma vez. Em experiência singular no estado, a Assembléia Legislativa de Mato Grosso do Sul aprovou por unanimidade a proposta do executivo que criou o Fundo de Investimentos Sociais (FIS), voltado exclusivamente para ações na área social.

O formato criado para o FIS seguiu o modelo comum encontrado em outras leis de incentivo a atividades, tais como a cultura, por exemplo. Com recursos inicialmente repassados pelo erário estadual ( $\mathrm{R} \$ 36,3$ milhões em 2000), o fundo teve como principal fonte arrecadadora a contribuição de empresas que, ao doarem recursos, ganhavam créditos que serviam para abater o Imposto sobre Circulação de Mercadorias e Serviços (ICMS) devido. Com isso, parte do que o governo arrecadaria com esse imposto de competência estadual foi compor o volume de recursos disponíveis do FIS. A aparente queda na arrecadação era absolutamente compensada com a redução dos recursos destinados ao pagamento de dívida estadual com a União, afinal contabilmente esses recursos "doados" por empresas e destinados ao FIS não eram arrecadação tributária, mas convertiam-se em dinheiro pronto para uso em investimentos e programas de grande importância social.

De maneira mais detalhada, constituíam receitas do FIS (Lei Estadual n. ${ }^{\circ}$ 2.105): a) contribuições de empresas interessadas em participar do programa, observado o disposto nos arts. $6^{\circ}$ e $7^{\circ}$; b) transferências à conta do Orçamento Geral do Estado; c) auxílios, subvenções e outras contribuições de entidades públicas ou privadas, nacionais ou estrangeiras; d) juros bancários e outros rendimentos de aplicações financeiras, inclusive os decorrentes de correção monetária; e) doações e legados; f) outros recursos a ele destinados e quaisquer outras rendas obtidas.

\footnotetext{
33 Para os números do orçamento do estado, ver a página da Auditoria-Geral do Estado de Mato Grosso do Sul na rede mundial de computadores, no endereço: http://www.unisite.ms.gov.br/unisite/sites/auditoriageral $/$ index.php?inside $=1 \&$ tp $=3 \&$ show $=6051$.

34 Idem.

35 CONSELHO DE GESTÃO ESTADUAL DE POLÍTICAS SOCIAIS (COGEPS). Fundo de Investimentos Sociais: combatendo a pobreza e promovendo a inclusão social. Campo Grande: Governo do Estado de Mato Grosso do Sul, 2002. p. 11. (Manual de Orientação)
} 
É bom lembrar que, de acordo com a Lei Estadual n. 2.105 (30/05/2000), a empresa interessada em contribuir para o FIS precisava obter antecipadamente autorização expressa da Secretaria de Estado da Fazenda de acordo com as normas estabelecidas por esse órgão. Isso era importante porque, a época, dentro de todas as possíveis fontes de receita, a contribuição de empresas visando crédito no ICMS compunha a mais importante para o fundo. Se em 2000, na criação do fundo (art. 12, Lei Estadual n. ${ }^{\circ}$ 2.105), o governo do estado estava autorizado a criar créditos no valor de $\mathrm{R} \$ 36,3$ milhões a fim de dar início às operações, a partir de 2001, conforme se vê na tabela 1, a seguir, o volume multiplica-se e o dinheiro veio cada vez mais das "contribuições" privadas ${ }^{36}$.

Tabela 1 - Investimento social realizado com recursos do FIS, 2002-2005

\begin{tabular}{lccccc} 
& & & \multicolumn{2}{c}{ (Em R\$ mil correntes) } \\
\hline Agricultura e Pecuária & $\mathbf{2 0 0 1}$ & $\mathbf{2 0 0 2}$ & $\mathbf{2 0 0 3}$ & $\mathbf{2 0 0 4}$ & $\mathbf{2 0 0 5}$ \\
Assistência Social e & $3.756,8$ & $7.423,0$ & $5.094,8$ & $9.008,9$ & $7.045,9$ \\
Cidadania Solidária e & $13.834,8$ & $10.312,7$ & $8.334,1$ & $12.634,2$ & $12.406,4$ \\
Economia Soliãã de Renda & $2.925,3$ & $1.196,4$ & $1.539,0$ & $1.776,9$ & $2.264,1$ \\
Geração & $16.538,7$ & $35.969,8$ & $32.517,1$ & $30.181,5$ & $35.157,4$ \\
Educação & $10.617,3$ & $9.980,8$ & $20.933,9$ & $13.584,5$ & $23.149,2$ \\
Habitação & - & $30.059,6$ & $28.425,0$ & $36.862,5$ & $34.678,7$ \\
Repasse aos municípios & $\mathbf{6 . 4 2 6 , 3}$ & $24.212,8$ & $31.133,5$ & $60.838,2$ & $46.469,0$ \\
Saúde & $\mathbf{5 4 . 0 9 9 , 2}$ & $\mathbf{1 1 9 . 1 5 5 , 1}$ & $\mathbf{1 2 7 . 9 7 7 , 4}$ & $\mathbf{1 6 4 . 8 8 6 , 8}$ & $\mathbf{1 6 1 . 1 7 0 , 8}$ \\
\hline Total do Ano & $\mathbf{2 . 0 7 8 , 8}$ & $\mathbf{2 . 3 9 6 , 4}$ & $\mathbf{2 . 8 9 5 , 2}$ & $\mathbf{3 . 4 6 1 , 3}$ & $\mathbf{4 . 0 3 9 , 4}$ \\
\hline Orçamento do Estado (em & & & & &
\end{tabular}

Fonte: Secretaria de Estado da Fazenda de Mato Grosso do Sul.

Não era todo esse recurso arrecadado na forma da lei, no entanto, que pertencia ao estado. Também de acordo com a Lei Estadual n. 2.105 (30/05/2000), uma parte, 25\% de toda contribuição das empresas via desconto no ICMS, deveria ser dirigida aos municípios sul-mato-grossenses. Estes, por sua vez, para terem acesso a essa parcela do FIS, eram obrigados a constituir estrutura semelhante à encontrada em nível estadual. Isto é, deveriam criar: a) por meio de lei, Fundos Municipais de Investimento Social, sob a égide dos poderes executivos municipais; b) comitês municipais de acompanhamento, fiscalização e também direcionamento dos recursos disponíveis e aplicados pelos fundos municipais. Esses comitês deveriam compor-se de no mínimo seis membros, sendo três indicados pelo poder executivo da cidade e mais três indicados pela sociedade civil organizada. Sua nomeação seria um ato do prefeito e seria publicada de acordo com os procedimentos legais normais.

O volume a ser depositado nos fundos municipais se fazia de acordo com o índice de participação do município na arrecadação do ICMS (Decreto Estadual n. 9.946) e acontecia até o quinto dia útil do mês subseqüente ao recolhimento do tributo. A Secretaria de Estado da Fazenda era órgão responsável pela arrecadação e repasse desses recursos.

Por tudo isso, a fim de evitar qualquer desvio de função dos recursos, tanto do FIS como dos fundos municipais, foi vetada qualquer utilização do dinheiro para pagamento de despesas com pessoal ou outra atividade-meio dos órgãos que operacionalizavam os investimentos sociais patrocinados (parágrafo único, art. $2^{\circ}$ da Lei Estadual n. 2.105 de 30/05/2000).

36 A aposta inicial do Governo do Estado de Mato Grosso do Sul era investir R \$ 36 milhões por ano em programas de inclusão social, como o Bolsa-Escola, o Banco do Povo, o Cidadania da Família, as Comunidades Indígenas, a Habitação Popular, o Prove-Pantanal, a Reforma Agrária e a Segurança Alimentar. Com o andamento e a legitimação da política instituída, como se viu pelo volume de recursos envolvidos, a abrangência tornou-se bem maior. 
Em outras palavras, o objetivo do FIS foi financiar ações, programas e investimentos no estado com o fim enfático de combate a pobreza e a exclusão social. Todavia, não se deve imaginar que o fundo tornou-se fonte de recursos exclusivamente para programas de transferência de renda, isto é, que, ao fim e ao cabo, apenas repassava dinheiro aos beneficiários mediante uma contrapartida, como, por exemplo, manter o filho na escola. O campo de atuação dos recursos arrecadados foi bastante amplo e pode ser sumarizado em três grandes eixos: a) financiamento dos programas de políticas social e de cidadania (transferência de renda, atendimento social a crianças, jovens e idosos, defensoria pública itinerante, etc.); b) programas de geração de emprego e renda (formação de cooperativas, microcrédito, etc.); c) investimento em infra-estrutura econômica e social (construção de casas populares, construção e reforma de unidades de atendimento à população, aquisição de equipamentos, etc.).

Diante disso e de maneira mais precisa, os recursos do FIS e dos Fundos Municipais de Investimento Social destinavam-se a programas, projetos e serviços sociais que garantissem:

a) padrões de qualidade e a garantia dos direitos de cidadania; b) atendimento das necessidades sociais, c) priorização da sobrevivência dos segmentos vulnerabilizados e em situações de risco; d) qualificação progressiva das necessidades básicas e dos padrões respectivos em decorrência dos avanços econômico, social e do estágio de civilidade da sociedade. ${ }^{37}$

O público prioritário eram os cidadãos e grupos que se encontravam em situação de vulnerabilidade e risco pessoal e social, entendendo-se por vulnerabilidade, famílias e/ou indivíduos com:

a)perda de vínculos de afetividade, pertencimento e sociabilidade; b) fragilidade pelos ciclos de vidas: criança,
adolescente, pessoa idosa; c) identidade estigmatizada em termos étnico, cultural e sexual; d) desvantagem
pessoal resultante de deficiência física, mental, sensorial; e) exclusão social pela pobreza e pelo acesso às
políticas públicas; f) inserção precária ou não-inserção no mercado de trabalho, formal ou informal" e risco
pessoal e/ou familiar em casos de: "a) desnutrição infantil; b) uso de substâncias psicoativas; c) trabalho
infantil; d) diferentes formas de violência advinda do núcleo familiar, grupos e indivíduos; e) HIV e Aids e
doenças degenerativas; f) abuso e exploração sexual; g) moradia que oferece risco de vida; h) estratégias de
sobrevivência que podem representar risco pessoal e social.

Tratava-se, portanto, de programas, projetos e ações com ênfase na atuação sobre questões de grande monta e cuja gravidade nunca fora superadas na história do país. Mais do que isso, formavam iniciativas sobre a complexidade de problemas que, atacados de maneira matricial e integrada, permitiam ser enfrentados em suas diferentes faces de exclusão social. Para tanto, as preocupações, em cujo centro estava muito mais a família do que o indivíduo, apontavam para uma série de ações que, embora tivessem caráter universal, ao comporem-se como um conjunto, terminavam por determinar um desenho específico dirigido às características dos grupos de maior vulnerabilidade localizados em suas áreas geográficas definidas.

O esforço, segundo Blanes et al. ${ }^{39}$, ao apresentar números detalhados, terminou por gerar uma menor dispersão de esforços e, até aquele momento, pareceu potencializar os impactos sobre as diversas carências das famílias e comunidades atendidas, marcadamente quando comparado com as mobilizações de épocas anteriores.

37 CONSELHO DE GESTÃO ESTADUAL DE POLÍTICAS SOCIAIS (COGEPS). Subsídios para a realização do diagnóstico socioeconômico da efetividade das políticas públicas do governo de Mato Grosso do Sul. Campo Grande: Governo do Estado de Mato Grosso do Sul, [200?]. (mímeo). 38 CONSELHO DE GESTÃO ESTADUAL DE POLÍTICAS SOCIAIS (COGEPS). Subsídios para a realização do diagnóstico socioeconômico da efetividade das políticas públicas do governo de Mato Grosso do Sul. Campo Grande: Governo do Estado de Mato Grosso do Sul, [200?]. (mímeo).

39 BLANES, Denise et al. Inclusão social: uma utopia possível. São Paulo: Cortez, 2006. 


\section{Alguns números e observações sobre os impactos}

A análise empreendida, até agora, sobre a inovação levada a cabo pelo Governo do Estado do Mato Grosso do Sul na aplicação e gestão de políticas sociais revela três resultados qualitativos que merecem destaque:

1. aplicação de instrumentos inovadores de política social em escala inédita;

2. compromisso compartilhado dos diferentes órgãos do governo envolvidos no enfrentamento da exclusão social, seguindo orientação matricial para organização dos trabalhos;

3. coordenação das ações de governo, isto é, ação planejada e acordada, seguindo um comando que envolvia secretários e governador, evitando desperdícios.

Esses avanços qualitativos, todavia, não parecem ter resultado em impactos sensíveis na realidade social de Mato Grosso do Sul tal como esperado inicialmente. Essa constatação fica ainda mais evidente quando comparada aos números brasileiros entre 2001 e 2007, período em que o Governo do Estado implantou e fez funcionar plenamente o novo modelo de política na área social. A comparação de onze séries de indicadores sociais mostra que os esforços do executivo sul-matogrossense não criaram nenhum descolamento sensível entre os números obtidos nessa Unidade da Federação e os apresentados pelo resto do Brasil.

Para chegar a esse julgamento, é útil separar os indicadores em três grandes temas, por meio de agrupamento que avaliem o impacto do novo modelo de políticas sociais implantado nesse estado. Assim, o primeiro tema observado é renda e pobreza. O Gráfico 1 mostra, por exemplo, a queda significativa da extrema pobreza. A boa notícia, no entanto, não apresenta divergência significativa em relação ao que acontece no restante do país no mesmo período. Ambas as séries, apesar das oscilações, apontam quedas importantes entre 2001 e 2007.

Gráfico 1 - Taxa de Extrema Pobreza (Brasil e Mato Grosso do Sul), 2001-2007

$(\mathrm{em} \%)$

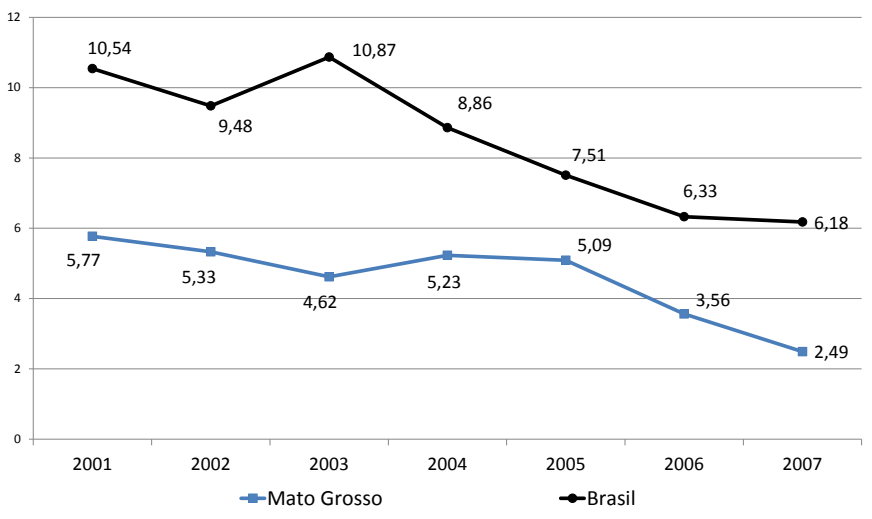

Fonte: (IPEA, 2012)

O mesmo se observa em relação à renda domiciliar per capita média (Gráfico 2). As séries para o estado de Mato Grosso do Sul e para o Brasil seguem trajetória muito semelhante, divergindo apenas no ano de $2007^{40}$.

40 Mesmo essa divergência foi passageira. No mesmo estudo utilizado para captação dos dados, observa-se que, nos anos seguintes, as trajetórias das rendas voltaram a aproximar-se. Ver INSTITUTO DE PESQUISA ECONÔMICA APLICADA (IPEA). Situação Social nos Estados: Mato Grosso do Sul. Brasília: IPEA, 2012. 
Gráfico 2 - Renda domiciliar per capita média (Brasil e Mato Grosso do Sul), 2001-2007

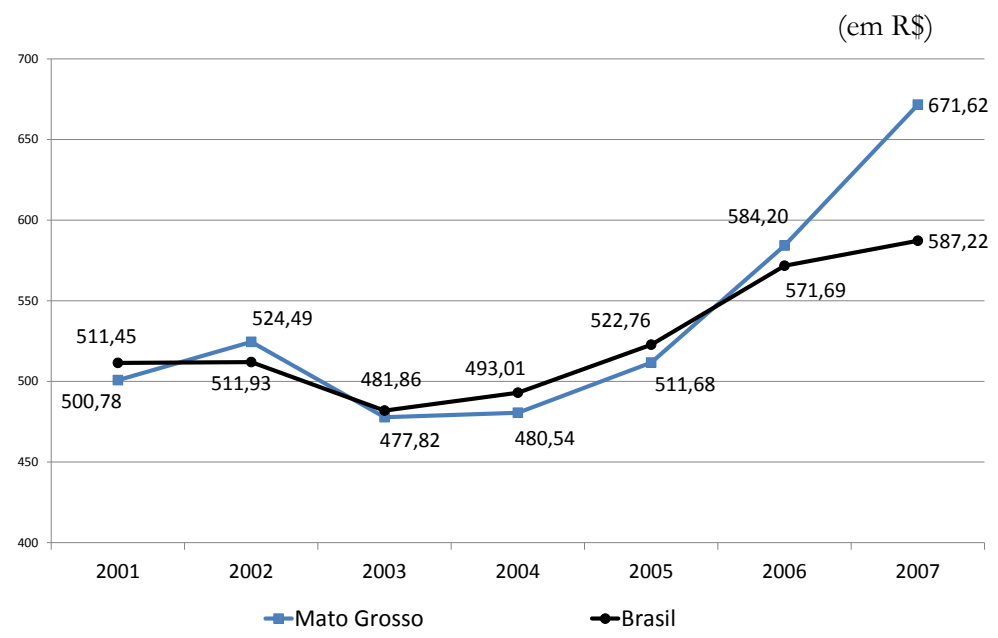

Fonte: (IPEA, 2012)

O Índice de Gini é série onde esperava-se maior descolamento entre o que acontecia no Brasil e o que se vivia em Mato Grosso do Sul (Gráfico 3). No entanto, a estabilidade na série estadual entre 2004 e 2006 - mesmo desconsiderando o ano de 2007 - mostra que o impacto das ações do governo local não foi capaz de diferenciar o nível de desigualdade nessa Unidade da Federação em relação ao vivido na média do país. Mais uma vez, o que se observa é a similaridade entre o que aconteceu no Brasil e o que sobreveio no Mato Grosso do Sul.

Gráfico 3 - Índice de Gini (Brasil e Mato Grosso do Sul), 2001-2007

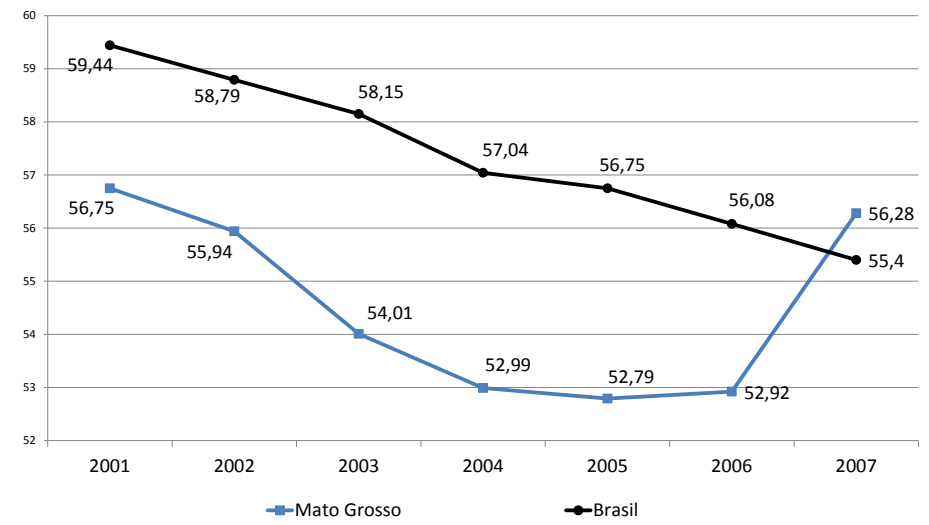

Fonte: (IPEA, 2012)

A taxa de mortalidade infantil, por sua vez, tem um desempenho piorado no estado em comparação ao restante do país. O Gráfico 4 mostra uma queda acentuada e ininterrupta no Brasil e uma redução menos firme do indicador no Mato Grosso do Sul. Além disso, em 2007, percebe-se um leve aumento do problema na Unidade da Federação em foco, reforçando a impressão de que o impacto do novo modelo de gestão de políticas sociais, ali implantado, não alcançou o resultado esperado. 
Gráfico 4 - Taxa de mortalidade infantil (Brasil e Mato Grosso do Sul), 2001-2007

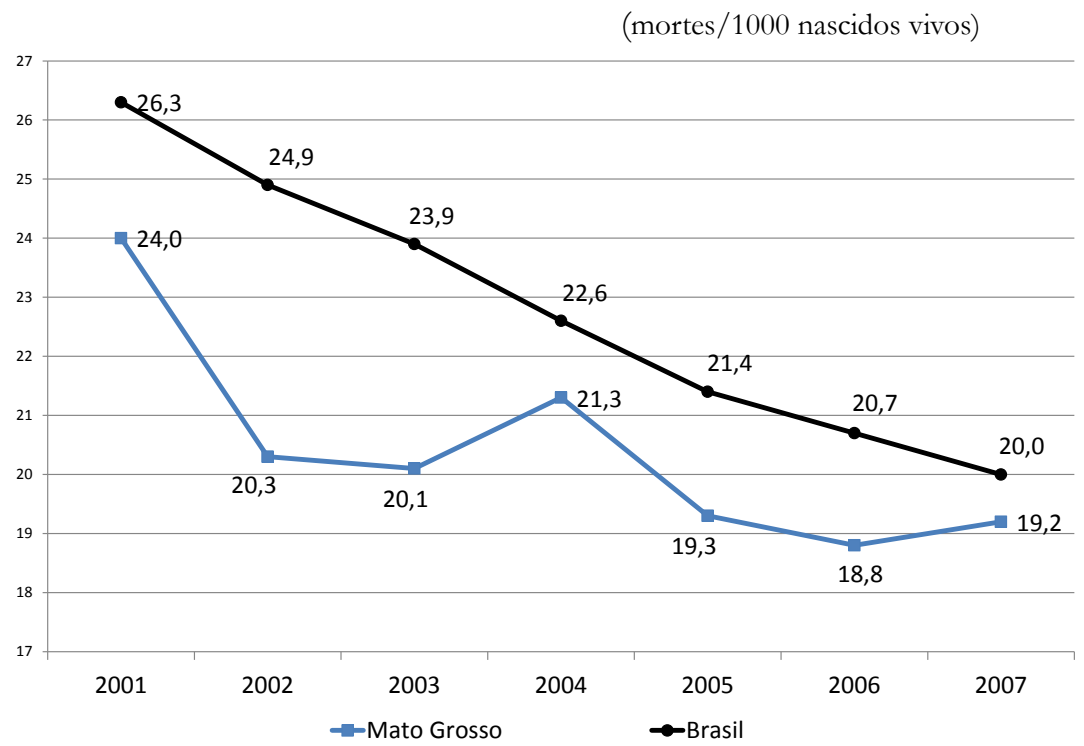

Fonte: (IPEA, 2012)

O quadro não muda muito quando se passa a analisar o segundo tema: educação. Observando o Gráfico 5, nota-se que o progresso na média de anos de estudo das população do Brasil e do Mato Grosso do Sul não apresentou divergência. Ambos os grupos vivenciaram um crescimento no tempo em sala de aula e a Unidade da Federação ainda sofreu, em 2003, rebaixamento relativo ao que acontecia no país.

Gráfico 5 - Média de anos de estudo (Brasil e Mato Grosso do Sul), 2001-2007

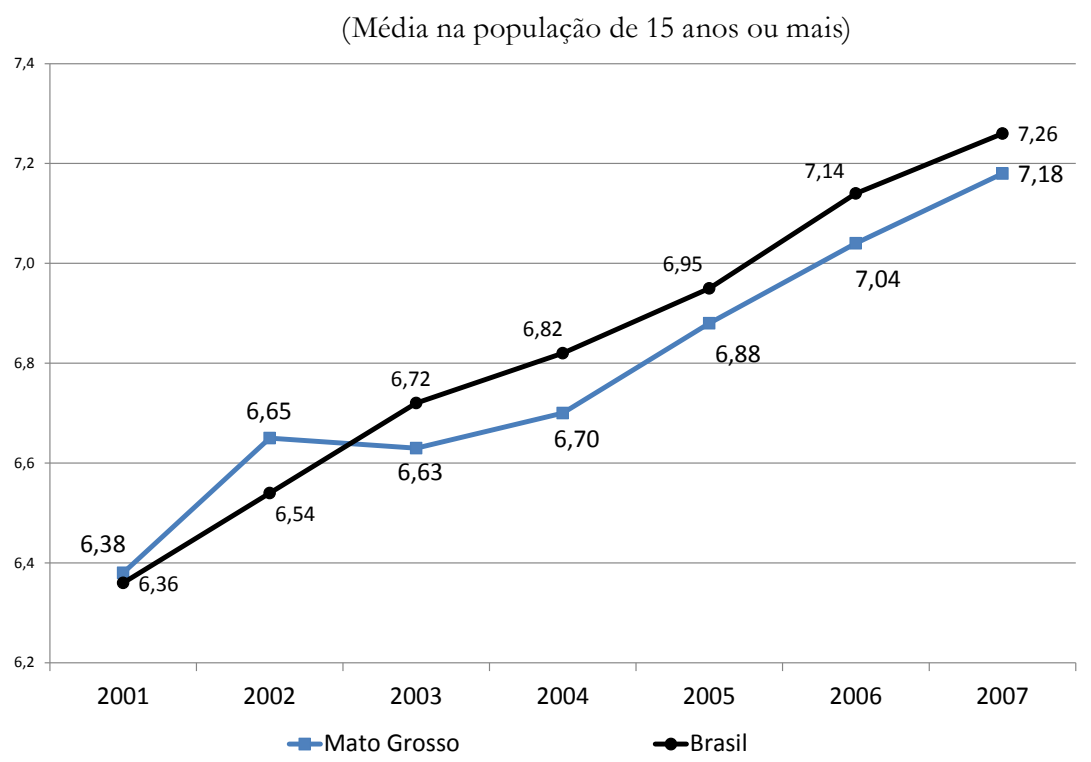

Fonte: (IPEA, 2012)

Quanto à taxa de analfabetismo, os resultados não são melhores. Mato Grasso do Sul apenas manteve sua posição relativa quando comparado ao resto do país (Gráfico 6). 
Gráfico 6 - Taxa de analfabetismo (Brasil e Mato Grosso do Sul), 2001-2007.

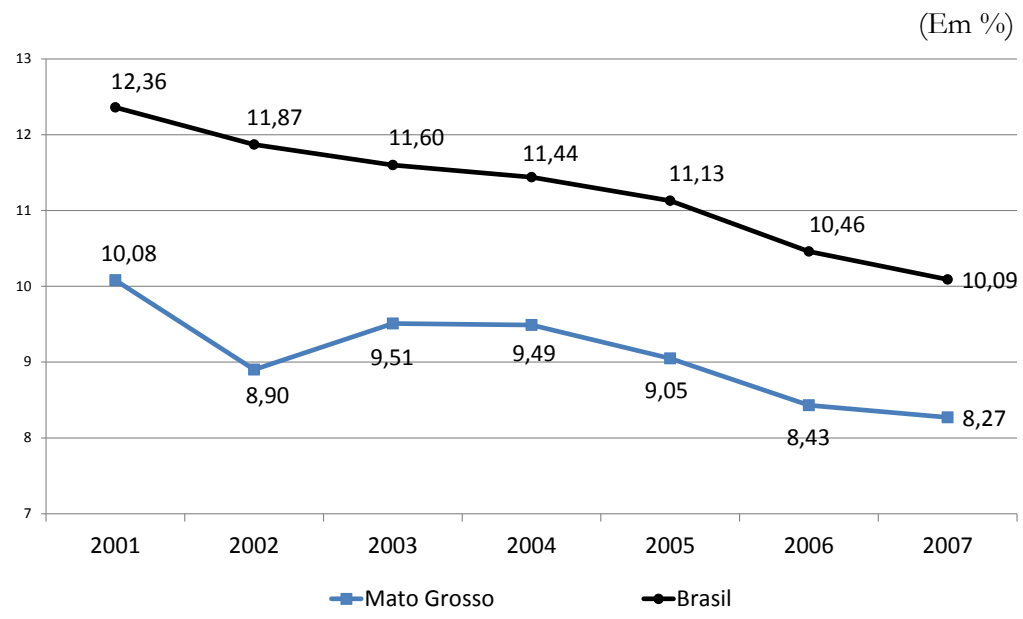

Fonte: (IPEA, 2012)

A taxa de frequência na escola ou creche na população de zero a cinco anos também repetiu o que foi observada nas variáveis anteriores: o Mato Grosso do Sul repetiu a tendência observada no país (Gráfico 7). Cabe chamar a atenção, no entanto, de que houve uma aproximação da taxa mais baixa vivida no estado e os números observados para o Brasil. Todavia, tal convergência não parece ser suficiente para indicar que o novo modelo de gestão das políticas sociais sul-mato-grossenses tenha diferenciado os resultados locais em relação ao que se viu nas demais unidades da federação.

Gráfico 7 - Taxa de frequência à escola ou creche - 0 a 5 anos (Brasil e Mato Grosso do Sul), 20012007.

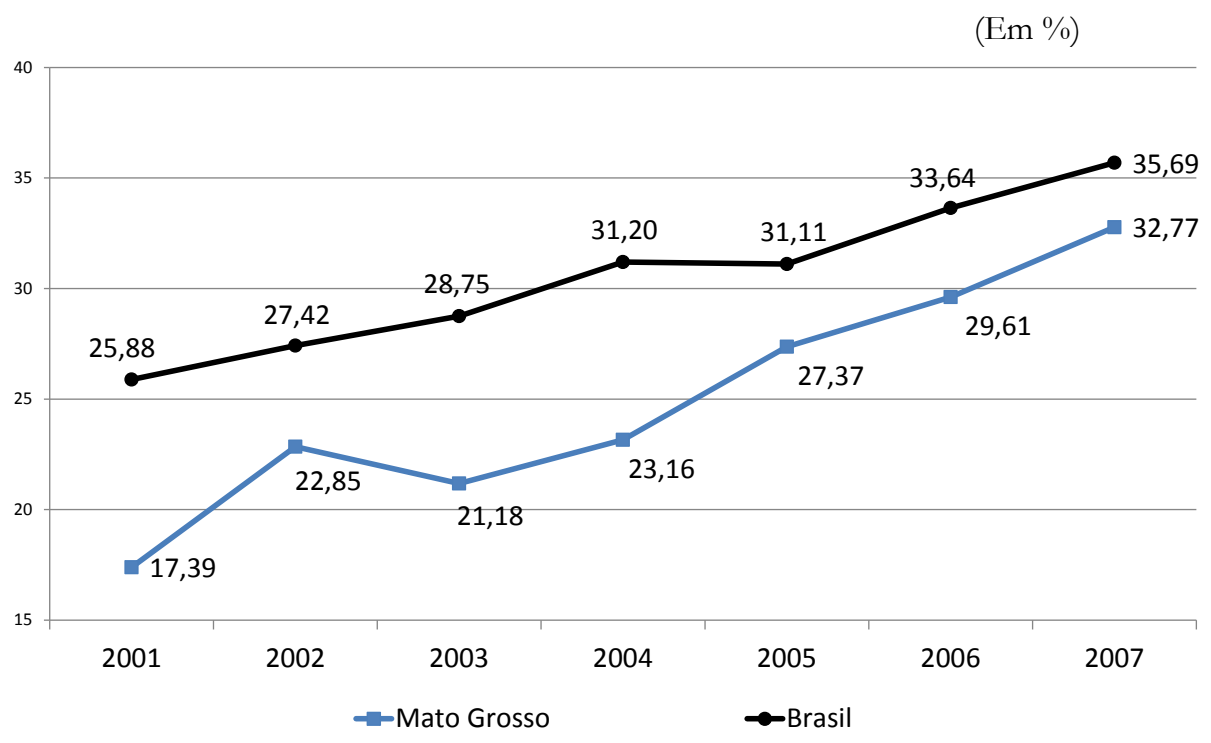

Fonte: (IPEA, 2012)

No último tema, infraestrutura e serviços voltados à habitação, os números comparados de Mato Grosso do Sul e Brasil também não apresentam tendências significativamente diferentes. O gráfico 8, por exemplo, mostra que o progresso desse estado na disponibilização adequada de água aos seus habitantes foi mais acelerado até 2006. A queda observada em 2007, porém, aponta para a dificuldade de manter a tendência dos esforços e resultados da ação do Governo Estadual. 
Gráfico 8 - Taxa de abastecimento adequado de água (Brasil e Mato Grosso do Sul), 2001-2007.

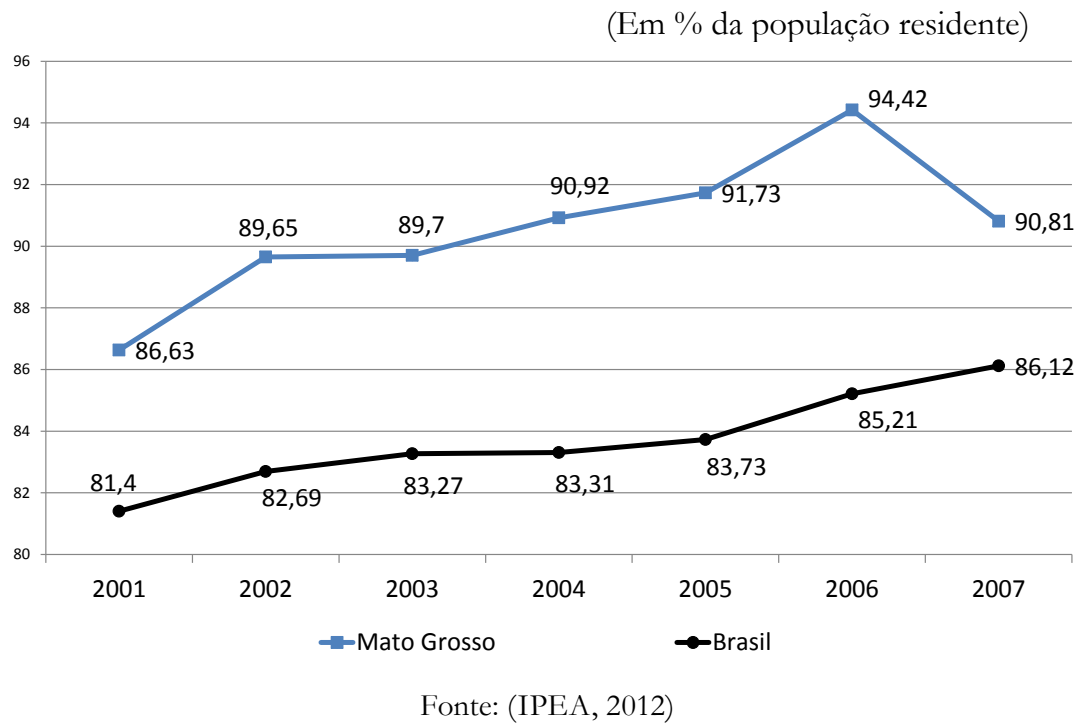

No acesso a energia elétrica, o estado sul-mato-grossense não poderia apresentar as mesmas taxas de melhoria observadas no resto do Brasil (Gráfico 9). Ali, os níveis de acesso à rede elétrica já eram elevados, alcançando, já em 2001, quase toda a população.

Gráfico 9- Acesso a energia elétrica (Brasil e Mato Grosso do Sul), 2001-2007.

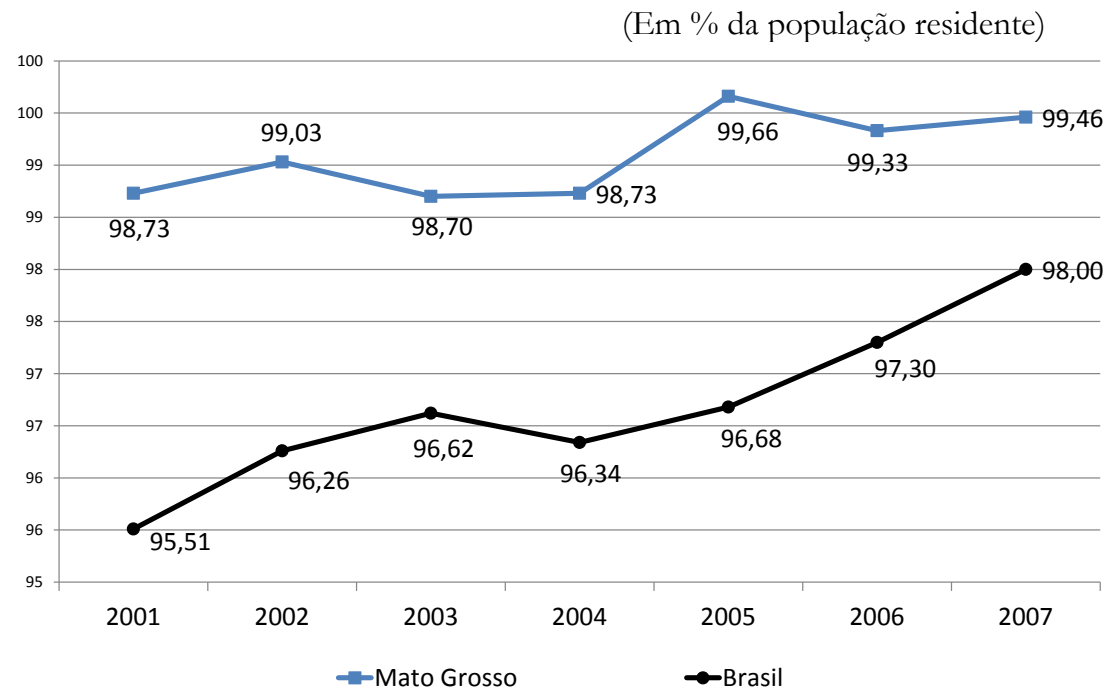

Fonte: (IPEA, 2012)

No lado oposto ao que se observou em relação ao acesso a energia elétrica, o Gráfico 10 mostra o quanto Mato Grosso do Sul está atrasado no fornecimento de esgotamento sanitário a sua população. Se no Brasil, em 2007, $3 / 5$ da população tinha acesso ao serviço, o mesmo acontecia com apenas $1 / 5$ dos habitantes do estado. É importante observar, entretanto, que, entre 2004 e 2007, a Unidade da Federação mais do que dobrou o percentual de acesso da população residente ao esgotamento sanitário. 
Gráfico 10 - Acesso a esgotamento sanitário adequado (Brasil e Mato Grosso do Sul), 2001-2007

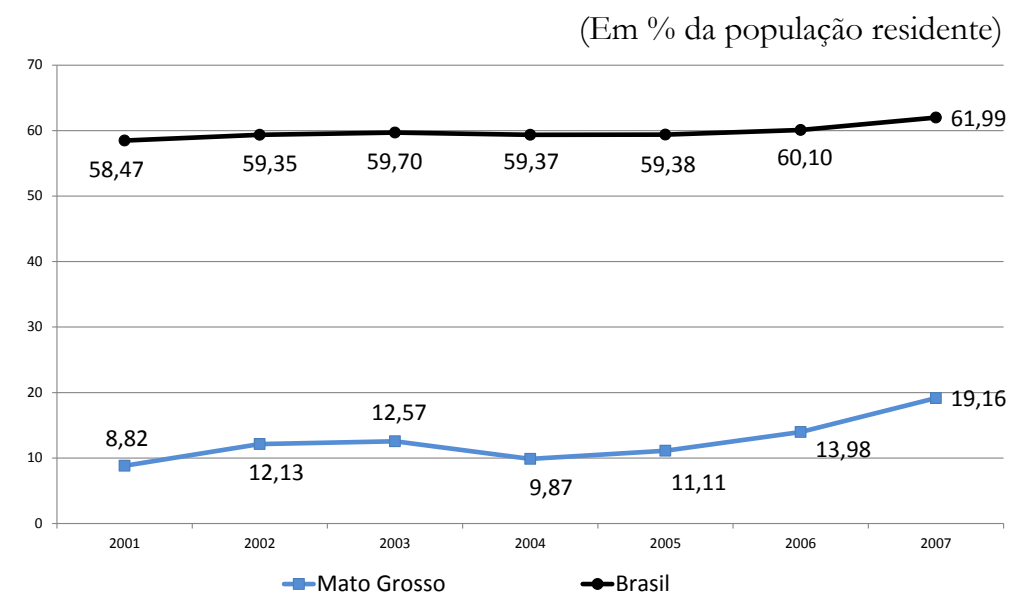

Fonte: (IPEA, 2012)

Observando o acesso à coleta de lixo (Gráfico 11), mais uma vez o estado sul-mato-grossense não se destaca dos avanços alcançados no restante do país. Entre 2001 e 2007, o Brasil elevou em 4\% o volume da população atendida por coleta de lixo. Por outro lado, o estado viu esse mesmo indicador crescer pouco mais de $3 \%$.

Gráfico 11 - Acesso a coleta de lixo (Brasil e Mato Grosso do Sul), 2001-2007

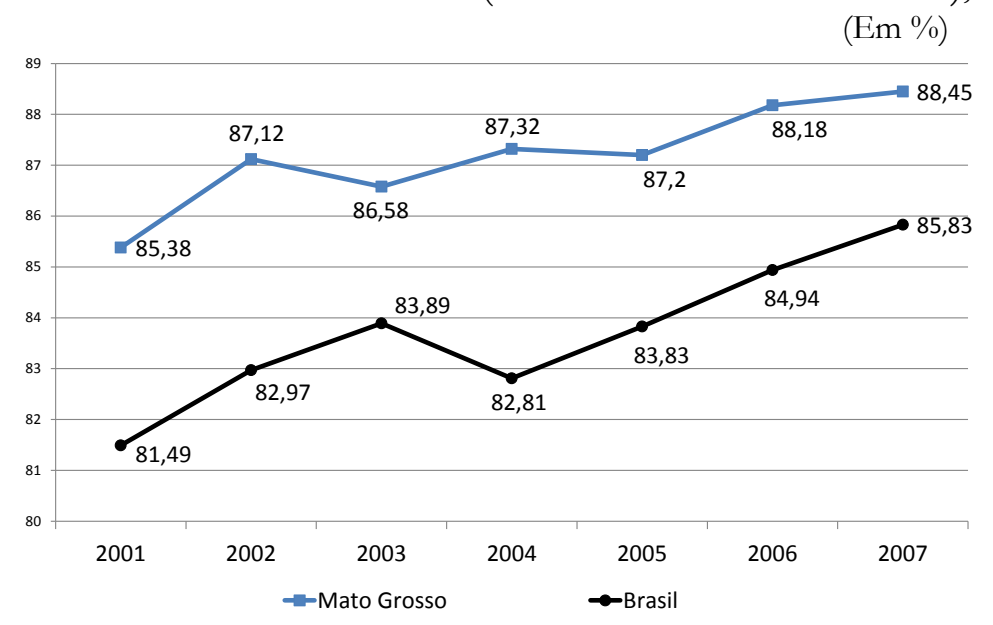

Fonte: (IPEA, 2012)

Assim, em resumo, os números apresentados não parecem destacar avanços diferenciados na problemática social do estado de Mato Grosso do Sul, marcadamente a partir do novo modelo de gestão das políticas sociais implantado no início dos anos 2000. Essa avaliação deixa novas perguntas ainda sem respostas: por que mudanças qualitativas bem desenhadas na gestão das políticas sociais não parecem ter surtido o impacto esperado? Por que, apesar da matricialidade e da coordenação, o Mato Grosso do Sul obteve resultados tão similares ao restante do país, onde não foram registradas mudanças importantes?

\section{Comentários finais}

O desenho e o aparente esforço empreendido pelo governo sul-mato-grossense naqueles anos representaram uma importante e inovadora ousadia em âmbito estadual. Não se tem notícia de esforços semelhantes nas diversas unidades da federação. Umas das poucas experiências similares debatidas na 
literatura sobre políticas sociais é a levada cabo em nível municipal pelas prefeituras de São Paulo no início dos anos $2000^{41}$ e, mais recentemente, em Osasco ${ }^{42}$.

No Mato Grosso do Sul, as iniciativas inovadoras do governo estadual tornaram possível que os recursos do FIS representassem, além de importante alavanca, a condição necessária, mas não suficiente, sobre a qual se tornava possível desenhar uma política integrada de atendimento às múltiplas carências das populações mais vulneráveis. A condição sine qua non para o bom funcionamento do conjunto era o compromisso do mandatário estadual. Assim, somadas às condições financeiras, por si só já inovadoras, e a decisão política, aparentemente partilhada pelos escalões gerenciais do governo, observou-se aperfeiçoamentos interessantes na construção e gestão da política social local.

Nesse sentido, as ações do estado tinham potencial para enfrentar o que, talvez, sejam as duas maiores críticas endereçadas às políticas públicas, marcadamente às sociais: a verticalização e a descoordenação. Os desvios causados por esses dois problemas costumam impedir e impedem arrostar adequadamente a multiplicidade de faces que compõem a exclusão social. A presença deles conduz, inexoravelmente, à dispersão de recursos, sobreposições, ausência de sinergia e, não menos importante, conflitos entre órgãos de governo.

Por isso mesmo, a experiência de Mato Grosso do Sul, criticável ou não, deveria representar um importante aprendizado para as três esferas de governo, sinalizando alternativas possíveis de desenho, construção, condução e avaliação de políticas. Apesar dos problemas -- e os resultados empíricos parecem apontar que os riscos não são poucos --, o desenho implementado pelo estado do Mato Grosso do Sul no combate de suas mazelas sociais parece constituir, ainda hoje, o programa realmente aplicado mais moderno visto no país.

\section{Referência}

AMORIM, Ricardo L. C. CF/88: economia e sociedade no Brasil. In: CARDOSO JUNIOR, José Celso. (Org.). $A$ Constituição Federal de 1988 Revisitada. Brasilia: Ipea, 2009.p. 9-33. v. 1.

AMORIM, Ricardo L. C. As diferentes dinâmicas regionais dentro da economia brasileira: o caso do Mato Grosso do Sul. Revista de Economia Mackenzie, São Paulo, v. 6, p. 113-148, 2008.

ANGEL, Héctor Sanín. Control de Gestión y Avaluación de Resultados en la Gerencia Pública. Santiago de Chile: CEPAL, 1999. (Serie Manuales).

ARANHA, Adriana V. (Org.). Fome Zero: uma história brasileira. Brasília: Ministério do Desenvolvimento Social e Combate à Fome, 2010. v. 2.

BACHA, Edmar. O Plano Real: uma avaliação. In: MERCADANTE, Aloisio (Org.). O Brasil Pós-Real: a política econômica em debate. Campinas: Unicamp, 1997.

BALTAR, Paulo. Estrutura Econômica e Emprego Urbano na Década de 1990. In: PRONI, Marcelo; HENRIQUE, Wilnes. Trabalho, Mercado e Sociedade: o Brasil nos anos 90. São Paulo: UNESP; IE-UNICAMP, 2003.

BARROS, R. P.; HENRIQUE, R., MENDONÇA, R. A estabilidade inaceitável: desigualdade e pobreza no Brasil. In: HENRIQUE, R. (Org.). Desigualdade e pobreza no Brasil. Rio de Janeiro: IPEA, 2000. p. 21-47.

BLANES, Denise et al. Inclusão social: uma utopia possível. São Paulo: Cortez, 2006.

BRASIL. Ministério do Desenvolvimento Social e Combate à FOME. Departamento de Prospecção para a Inclusão Produtiva. Acelerar a Inclusão Produtiva. Brasília: MDS, 2010.

CARVALHO, José M. A Cidadania no Brasil: o longo caminho. Rio de Janeiro: Civilização Brasileira, 2001.

41 POCHMANN, M. (Org.). Desenvolvimento, trabalho e solidariedade. São Paulo: Cortez e Fund. Perseu Abramo, 2002.

42 CAZZUNI, Dulce et al. Atlas da exclusão social de Osasco. São Paulo: DIEESE; SDTI/PMO, 2007. 
CAZZUNI, Dulce et al. Atlas da exclusão social de Osasco. São Paulo: DIEESE; SDTI/PMO, 2007.

CONSELHO DE GESTÃO ESTADUAL DE POLÍTICAS SOCIAIS (COGEPS). Fundo de Investimentos Sociais: combatendo a pobreza e promovendo a inclusão social. Campo Grande: Governo do Estado de Mato Grosso do Sul, 2002. (Manual de Orientação).

CONSELHO DE GESTÃO ESTADUAL DE POLÍTICAS SOCIAIS (COGEPS). Subsidios para a realização do diagnóstico socioeconômico da efetividade das políticas públicas do governo de Mato Grosso do Sul. Campo Grande: Governo do Estado de Mato Grosso do Sul, 2002.

DATHEIN, Ricardo. Brasil: vinte e cinco anos de estagnação econômica. In: ENCONTRO NACIONAL DE ECONOMIA POLÍTICA, 11., 2006, Vitória. Anais... Vitória: SEP, 2006.

FAGNANI, Eduardo. Ajuste econômico e financiamento da política social brasileira: notas sobre o período 1993/1998. Economia e Sociedade, Campinas: IE/UNICAMP, n.13, p. 155-178, 1999.

FILGUEIRAS, Luiz. História do Plano Real: fundamentos, impactos e contradições. São Paulo: Boitempo, 2000.

FIORI, José L. Reforma ou Sucata: o dilema estratégico do setor público brasileiro. São Paulo: IESP/FUNDAP, 1991. (Texto para Discussão, n. 4).

FREEMAN, Chris; LOUÇÃ, Francisco. As Time Goes By. Oxford: Oxford University Press, 2001.

FURTADO, Celso. O mito do desenvolvimento econômico. São Paulo: Paz e Terra, 1974.

MATO GROSSO DO SUL. Balanço do Governo Popular: 1999-2006. Campo Grande: Governo do Estado de Mato Grosso do Sul, 2006.

INSTITUTO BRASILEIRO DE GEOGRAFIA E ESTATÍSTICA (IBGE). Contas Regionais. Banco de dados. Disponível em: <www.ibge.gov.br>. Acesso em: 3 abr. 2014.

INSTITUTO DE PESQUISA ECONÔMICA APLICADA (IPEA). Situação Social nos Estados: Mato Grosso do Sul. Brasília: IPEA, 2012.

LACZYNSKI, Patricia. Programa Integrado de Inclusão Social. Disponível em: < http:/ /www.polis.org.br/publicacoes/ dicas/dicas_interna.asp?codigo=32>. Acesso em: 23 abr. 2014.

OLIVEIRA, Carlos; HENRIQUE, Wilnes. Determinantes da Pobreza no Brasil: um roteiro de estudo. São Paulo em Perspectiva (revista da Fundação SEADE), v.4, n.2, abril-junho de 1990.

POCHMANN, Marcio; AMORIM, Ricardo L. C. (Org.). Atlas da exclusão social no Brasil. São Paulo: Cortez, 2002.

POCHMANN, Marcio. (Org.). Desenvolvimento, trabalho e solidariedade. São Paulo: Cortez e Fund. Perseu Abramo, 2002.

RODRÍGUEZ, Octavio. O Estruturalismo Latino-Americano. Rio de Janeiro: Civilização Brasileira, 2009.

ROUSSEAU, Jean. J. Discurso sobre a origem e os fundamentos da desigualdade entre os Homens. São Paulo: Abril, 1973.

TAVARES, Maria C. A economia política do real. In: MERCADANTE, Aloisio (Org.). O Brasil Pós-Real: a política econômica em debate. Campinas: Unicamp;IE, 1997.

TELLES, Vera. Direitos sociais (afinal do que se trata?). Belo Horizonte: UFMG, 2001. 
Para publicar na revista Brasileira de Políticas Públicas, acesse o endereço eletrônico www.rbpp.uniceub.br

Observe as normas de publicação, para facilitar e agilizar o trabalho de edição. 